\title{
Plasmon analysis of Triticum (wheat) and Aegilops. 1. Production of alloplasmic common wheats and their fertilities
}

\author{
Koichiro Tsunewaki ${ }^{1 * *}$, Gui-Zhi Wang ${ }^{2}$ and Yoshihiro Matsuoka ${ }^{1}$ \\ ${ }^{1}$ Department of Bioscience, Fukui Prefectural University, Matsuoka, Fukui 910-11, Japan \\ ${ }^{2}$ Laboratory of Genetics, Faculty of Agriculture, Kyoto University, Kyoto 606-01, Japan
}

(Received 9 September 1996, accepted 16 October 1996)

\begin{abstract}
Plasmons (= cytoplasms) of eight Triticum species (ten accessions) and 24 Aegilops species (36 accessions) have been introduced by repeated backcrosses to 12 genotypes of hexaploid, common wheat. At transfer problems such as crossing barrier, preferential transmission of a gametocidal or parthenogenesis-inducing chromosome, and mistagging of the material occurred, all of which hindered the plasmon transfer program. Of the 552 genotype-plasmon combinations produced, $532(96.4 \%)$ had reached the $\mathrm{B}_{10}$ or a later backcross generation, $15(2.7 \%)$ the $\mathrm{B}_{7} \sim \mathrm{B}_{9}$ generation, and the remaining $5(0.9 \%)$ the $\mathrm{B}_{4} \sim \mathrm{B}_{6}$ generation by summer, 1996 . Pollen and selfed seed fertilities were observed in plants of all the field-grown lines in the 1992 - 1993 winter crop season, and backcrossed and selfed seed fertilities of plants grown in a greenhouse under a long day condition (17-h light) were assessed in the five latest backcross generations. Selfed seed fertility was found to be a better parameter of male fertility than was pollen fertility. Female fertility, as estimated from the backcrossed seed fertility, was about three times more tolerant to genetic stress caused by the alien plasmon transfer than was male fertility evaluated from both the pollen and selfed seed fertilities. The plasmons studied could be classified into 14 fertility spectrum groups. Most, excluding 15 plasmons belonging to the $\mathrm{B}, \mathrm{D}, \mathrm{D}^{2}, \mathrm{~S}$, and $\mathrm{S}^{\mathrm{b}}$ plasmon types, were considered the male sterile plasmon to common wheat.
\end{abstract}

\section{INTRODUCTION}

Genetic information carried by a eukaryotic organism is divided into a "genome" in the nucleus and a "plasmon" in the cytoplasm (Wettstein, 1924). The plasmon of a plant is further divided into a "plastome" (chloroplast genome) in the chloroplast and "chondriome" (mitochondrial genome) in the mitochondrion (ref. Rieger et al., 1991). As the major portion of the genetic information of an organism is stored in its genome, the nucleus is of the prime importance in heredity and has an essential role in eukaryotic evolution. Genetic studies on speciation and phylogeny in different plant and animal taxa mainly have focused on relationships among the genomes, chromosomes or genes (nuclear) of related taxa. Plasmon evolution, however, has received less attention. Michaelis (1954) made extensive investigations of the plasmons of the genus Epilobium, but the species studied were limited to $E$. hirsutum and E. luteum because of the strong cross incompatibility that exists between Epilobium species.

\footnotetext{
* Corresponding author.
}

He showed that these two species differ in their plasmons. Using the genus Oenothera in which the plastome is biparentally transmitted, Stubbe (1964) studied the interaction between the genomes and plastomes of species belonging to the subgenus Euoenothera by comparing the phenotypes of their $F_{1}$ hybrids. He obtained important information on genome-plastome compatibility and the competitive abilities of different plastomes.

In Triticum (wheat genus) and the related Aegilops genus the genetic barrier to artificial interspecific and intergeneric crossing is less pronounced, and all the species can be crossed as female to polyploid wheats. Moreover, further backcrosses with the polyploid wheat as the recurrent pollen parent give viable offspring. In addition, their plasmons are transmitted maternally to the offspring (Fukasawa, 1959; Tsunewaki, 1996). These conditions allow the transfer of the plasmons of all Triticum and Aegilops species into the same polyploid wheats. By equalizing the effects of the genomes, the ability to critically compare the plasmons of different species is facilitated. In fact, Maan (1975a), Panayotov (1983), and Suemoto (1983) produced a large number of alloplasmic 
wheats that have plasmons of different Triticum, Aegilops, Secale, and even Agropyron species and showed the plasmon differences between those species.

The purpose of our study was to obtain an overall picture of plasmon differentiation in the Triticum - Aegilops complex in order to show the phylogenetic relationships that exist between the plasmons of all the species in these two genera and to clarify the maternal lineages of the plasmons of the polyploid species. To do this, a set of 46 alloplasmic lines has been produced by repeated backcrosses in each of 12 common wheats (genome donors or alloplasmon recipients; all $2 \mathrm{n}=6 \mathrm{x}=42$, genome constitution AABBDD) by introducing into them 46 plasmons from practically all the species of the two genera (plasmon donors). The phenotypic characteristics of all the alloplasmics produced have been compared to each other and to the characteristics of the corresponding euplasmics (control) in order to characterize the individual plasmons.

The production of the necessary wheat alloplasmics was started in 1966 and was nearly completed in 1993 after 28 years of work, as most had reached the 10 th $\left(\mathrm{B}_{10}\right)$ or a later backcross generation. We studied the various characters of all the lines, including the corresponding euplasmics, by growing them in field plots during the 1992 - 1993 winter crop season, the plots being specifically arranged to allow statistical analyses of the data.

The results obtained will be presented in three consecutive articles. This, the first of the series, deals with the production of the alloplasmic wheats and their pollen and seed fertilities. The second will deal with other phenotypic characteristics of the individual plasmons, and the third with the interaction between the genomes and plasmons.

From previous findings of organellar DNA differences (Tsunewaki, 1993, for review) and the phenotypic effects described here, all the plasmons are classifiable into 22 plasmon types (ref. column one of Table 2 in this article). In this and later articles, these plasmon types often will be cited to make the description concise and to aid the reader's understanding.

\section{MATERIALS AND METHODS}

Alloplasmon recipients. The phenotype of an alloplasmic line is determined by the interaction between the genome and plasmon; therefore, it is important to select suitable alloplasmon recipients for the production of alloplasmics in order to make effective distinctions between different plasmons using the phenotypes of the alloplasmics produced. It is preferable to use a di- or tetraploid as the recipient rather than hexaploids, because the effects of alloplasmons are more sensitively expressed in the lower ploidies. From previous experience, however, we know that even the alloplasmics of tetraploids show strong deleterious effects of many alloplasmons, and their production and maintenance are time-consuming, though not impossible. To produce alloplasmic wheats that have plasmons of all the Triticum and Aegilops species, we used only hexaploids as the alloplasmon recipient. The 12 common wheats shown in Table 1 were selected on the following basis: (1) They were representative strains of each of the common wheat species, except for $T$. vavilovii, a variant of $T$. spelta; (2) strains previously were known to be useful for discriminating, at the least, certain plasmons; and (3) strains were of historical importance in plasmon studies. Detailed characteristics of each selected recipient are given in Tsunewaki (1980). Hereafter, all the plasmon recipients are indicated by their abbreviated names given in the last column of Table 1.

Table 1. Alloplasmon recipients (all $2 n=6 x=42$, genome constitution AABBDD) used to produce alloplasmic wheats

\begin{tabular}{|c|c|c|}
\hline Code & Alloplasmon recipient & Abbrev. \\
\hline A & T. aestivum var. erythrospermum & Tve \\
\hline B & T. aestivum strain P168 & P168 \\
\hline $\mathrm{C}$ & T. aestivum cv. Chinese Spring & CS \\
\hline $\mathrm{D}$ & T. aestivum cv. Norin 26 & $\mathrm{~N} 26$ \\
\hline $\mathrm{E}$ & T. aestivum strain Salmon & Slm \\
\hline $\mathrm{F}$ & T. aestivum cv. Jones Fife & JF \\
\hline G & T. aestivum cv. Selkirk & Sk \\
\hline $\mathrm{H}$ & T. aestivum cv. S-615 & $\mathrm{S} 615$ \\
\hline $\mathrm{I}$ & T. sphaerococcum var. rotundatum & Sphr \\
\hline $\mathrm{J}$ & T. compactum cv. No. 44 & $\mathrm{Cmp}$ \\
\hline K & T. spelta var. duhamelianum & Splt \\
\hline $\mathrm{L}$ & T. macha var. subletschchumicum & Mch \\
\hline
\end{tabular}

Plasmon donors. One to five accessions from each genome type of Triticum and Aegilops were the plasmon donors; totally 46 accessions. All the alloplasmon donors with their abbreviated names and some other information are listed in Table 2. Hereafter both the plasmon and its donor are shown by the same abbreviated name. Alloplasmic lines also are indicated by the names of the plasmon donor (in parentheses) and recipient, a hyphen being placed between the two names.

Production of alloplasmic wheat lines. All the plasmon donors first were crossed as female to one or a few plasmon recipients, after which the hybrids produced were repeatedly backcrossed with all 12 recipients as the recurrent pollen parents. Many diploid plasmon donors, however, did not produce viable $\mathrm{F}_{1}$ hybrids when crossed to the common wheats. To overcome this crossing barrier, the triploid hybrids produced between them and an emmer wheat (btc, cms, spl.4 and some other plasmons), amphidiploids (CCUU for $c d t 2$, SSAA for $s p l 1, \mathrm{~S}^{\mathrm{s}} \mathrm{S}^{\mathrm{s}} \mathrm{AA}$ for srs and $\mathrm{S}^{\prime} \mathrm{S}^{\mathrm{A}} \mathrm{AABB}$ for $\operatorname{lng}$ plasmon) or autotetraploids (shr plasmon) were crossed as female to the common wheats. 
Table 2. Sources of the plasmons used

\begin{tabular}{|c|c|c|c|c|c|c|}
\hline \multicolumn{4}{|c|}{ Plasmon } & \multicolumn{3}{|l|}{ Plasmon donor } \\
\hline Type & Abbr. & Code & Source & Species \& accession & $\begin{array}{r}\text { Chrom. } \\
\text { no.(n) }\end{array}$ & $\begin{array}{r}\text { Genome }^{\text {a) }} \\
\text { (haploid) }\end{array}$ \\
\hline $\mathrm{A}$ & $b t c$ & 01 & Tsunewaki & T. boeoticum aegilopoides & 7 & A \\
\hline $\mathrm{A}_{2}$ & $m n c$ & 16 & Panayotov & T. monococcum flavescens & 7 & $\mathrm{~A}$ \\
\hline $\mathrm{B}$ & $d c d^{\mathrm{b})}$ & 21 & Tsunewaki & T. dicoccoides spontaneonigrum & 14 & $\mathrm{AB}$ \\
\hline $\mathrm{B}$ & $d c m$ & 22 & Tsunewaki & T. dicoccum 'Vernal' & 14 & $\mathrm{AB}$ \\
\hline $\mathrm{B}$ & ast 1 & 52 & $\left(\right.$ euplasmic $\left.{ }^{c}\right)$ & common wheat (control) & 21 & $\mathrm{ABD}$ \\
\hline $\mathrm{B}$ & ast 2 & 11 & Panayotov & T. aestivum 'Penjamo' & 21 & $\mathrm{ABD}$ \\
\hline $\mathrm{B}$ & ast 3 & 58 & Tsunewaki & T. aestivum tibetanum & 21 & $\mathrm{ABD}$ \\
\hline $\mathrm{C}$ & $c d t 1$ & 02 & Kihara & Ae. caudata polyathera KU6-1 & 7 & $\mathrm{C}$ \\
\hline $\mathrm{C}$ & $c d t 2^{\mathrm{b}\rangle}$ & 27 & Tsunewaki & Ae. caudata & 7 & $\mathrm{C}$ \\
\hline $\mathrm{C}^{2}$ & $\operatorname{trn} 2$ & 38 & Panayotov & Ae. triuncialis & 14 & $\mathrm{UC}$ \\
\hline $\mathrm{D}$ & $s q r 1$ & 04 & Kihara & Ae. squarrosa typica KU20-2 & 7 & $\overline{\mathrm{D}}$ \\
\hline $\mathrm{D}$ & sqr2 & 19 & Sasakuma & Ae. squarrosa anathera KU2009 & 7 & $\mathrm{D}$ \\
\hline $\mathrm{D}$ & $c y l$ & 28 & Tsunewaki & Ae. cylindrica & 14 & $\mathrm{CD}$ \\
\hline $\mathrm{D}$ & vnt & 36 & Tsunewaki & Ae. ventricosa KU22-4 & 14 & $\mathrm{DN}$ \\
\hline $\mathrm{D}^{2}$ & $\operatorname{crs} 1$ & 35 & Maan & Ae. crassa & 14 & $\mathrm{DM}$ \\
\hline $\mathrm{D}^{2}$ & $\operatorname{crs} 2$ & 55 & Sakamoto & Ae. crassa KU21-4 & 21 & $\underline{\mathrm{DDM}}$ \\
\hline $\mathrm{D}^{2}$ & jon & 53 & Sakamoto & Ae. juvenalis & 21 & $\overline{\mathrm{DMU}}$ \\
\hline $\mathrm{D}^{2}$ & $v v l$ & 56 & Ohtsuka & Ae. vavilovii & 21 & $\underline{\mathrm{DMS}}$ \\
\hline $\mathrm{G}$ & spl3 & 15 & Maan & Ae. speltoides ligustica & 7 & $\mathrm{~S}$ \\
\hline $\mathrm{G}$ & $\operatorname{arr} 1$ & 23 & Tsunewaki & T. araraticum & 14 & $\mathrm{AG}$ \\
\hline $\mathrm{G}$ & $\operatorname{arr} 2$ & 24 & Maan & T. araraticum & 14 & $\mathrm{AG}$ \\
\hline $\mathrm{G}$ & $t m p$ & 25 & Schmidt & T. timopheevi & 14 & $\mathrm{AG}$ \\
\hline $\mathrm{G}$ & $z h k$ & 51 & Maan & T. zhukovskyi & 21 & AAG \\
\hline $\mathrm{G}^{2}$ & spl2 & 09 & Panayotov & Ae. speltoides aucheri & 7 & $\mathrm{~S}$ \\
\hline M & $\mathrm{cms}$ & 05 & Tsunewaki & Ae. comosa thessalica KU17-2 & 7 & M \\
\hline $\mathrm{M}^{\mathrm{h}}$ & $h l d$ & 06 & Panayotov & Ae. heldreichii & 7 & M \\
\hline $\mathrm{M}^{\mathrm{o}}$ & ovt & 31 & Fukasawa & Ae. ovata & 14 & $\mathrm{UM}$ \\
\hline $\mathrm{N}$ & unr & 07 & Maan & Ae. uniaristata & 7 & $\mathrm{~N}$ \\
\hline $\mathrm{S}$ & $\operatorname{spl} 1^{\mathrm{b})}$ & 08 & Tsunewaki & Ae. speltoides ligustica & 7 & $\mathrm{~S}$ \\
\hline $\mathrm{S}$ & spl4 & 17 & Tsunewaki & Ae. speltoides aucheri KU2201B & 7 & $\mathrm{~S}$ \\
\hline $\mathrm{S}^{\mathrm{b}}$ & bcr & 12 & Maan & Ae. bicornis & 7 & $\mathrm{~S}^{\mathrm{b}}$ \\
\hline $\mathrm{S}^{1}$ & $s h r$ & 10 & Sakamoto & Ae. sharonensis KU5-1 & 7 & $\mathrm{~S}^{1}$ \\
\hline $\mathrm{S}^{12}$ & $\ln g^{b)}$ & 20 & Tsunewaki & Ae. longissima TL05 & 7 & $\mathrm{~S}^{1}$ \\
\hline $\mathrm{S}^{v}$ & $s r s^{b\}}$ & 18 & Tsunewaki & Ae. searsii & 7 & $\mathrm{~S}^{\mathrm{s}}$ \\
\hline$S^{v}$ & $k t s 1$ & 33 & Sakamoto & Ae. kotschyi KU14-2 & 14 & US \\
\hline $\mathrm{S}^{\mathrm{v}}$ & $k t s 2$ & 39 & Tsunewaki & Ae. kotschyi & 14 & US \\
\hline $\mathbf{S}^{v}$ & $v r b$ & 34 & Sakamoto & Ae. variabilis KU13-1 & 14 & $\mathrm{US}$ \\
\hline $\mathrm{T}$ & $m t c 1$ & 13 & Maan & Ae. mutica & 7 & $\mathrm{~T}$ \\
\hline $\mathrm{T}^{2}$ & $m t c 2$ & 14 & Panayotov & Ae. mutica & 7 & $\mathrm{~T}$ \\
\hline $\mathrm{U}$ & $u m b$ & 03 & Muramatsu & Ae. umbellulata & 7 & $\mathrm{U}$ \\
\hline $\mathrm{U}$ & $\operatorname{trn} 1$ & 26 & Tsunewaki & Ae. triuncialis & 14 & UC \\
\hline $\mathrm{U}$ & $b n c 1$ & 29 & Sakamoto & Ae. biuncialis KU12-1 & 14 & $\mathrm{UM}$ \\
\hline $\mathrm{U}$ & $b n c 2$ & 37 & Panayotov & Ae. biuncialis macrochaeta & 14 & $\mathrm{UM}$ \\
\hline $\mathrm{U}$ & $\operatorname{trr} 1$ & 32 & Tsunewaki & Ae. triaristata & 14 & $\mathrm{UM}$ \\
\hline $\mathrm{U}$ & $\operatorname{trr} 2$ & 54 & Sakamoto & Ae. triaristata KU10-1 & 21 & $\mathrm{UMN}$ \\
\hline $\mathrm{U}$ & trr3 & 57 & Panayotov & Ae. triaristata recta & 21 & UMN \\
\hline $\mathrm{U}^{2}$ & $\mathrm{clm}$ & 30 & Sakamoto & Ae. columnaris KU11-2 & 14 & $\mathrm{UM}$ \\
\hline
\end{tabular}

a) After Kihara and Tanaka (1970) and Kimber and Tsunewaki (1988). Modified genomes are underlined.

b) Five plasmons, $d c d, c d t 2, s p l 1$, lng and $s r s$, were extracted from the artificial amphiploids, AABBDD, CCUU, SSAA, $\mathrm{S}^{1} \mathrm{~S}^{1} \mathrm{AABBDD}$ and $\mathrm{S}^{\mathrm{s}} \mathrm{S}^{\mathrm{s}} \mathrm{AA}$, produced respectively by Kihara, Kondo, Riley, Tsujimoto, and Feldman.

c) Euplasmic lines of 12 genome donors used as controls.

d) This accession (KU2927) originally was classified as Ae. triuncialis var. constantinopolitana, but recently corrected to Ae. kotschyi accession by morphological, cytological, and organellar DNA analyses.

Repeated backcrossing was started with these hybrids. The tetra- and hexaploid plasmon donors did not show severe cross incompatibility with the recipient hexaploids, except for those that carried gametocidal genes (described later).

Of the 12 plasmon recipients, Mch was exceptional in that it carries the $C h 1$ gene for hybrid chlorosis, whereas all the others had the complementary gene, Ch2. 
Therefore, when transfer of an alloplasmon from one of the 11 recipients to Mch was necessary, a bridge cross using an experimental line of the genotype $\operatorname{ch} 1 \operatorname{ch} 1 \operatorname{ch} 2 \operatorname{ch} 2$ was made. Hybrid chlorosis inevitably caused delay in the production of the alloplasmic Mch lines.

In the early stage of the work (up to 1976), all the materials were grown in the field, where the backcrossings were made. Since 1977, most of the backcrossing has been done with materials grown in a greenhouse under a long day condition of ca. 17-h light. We have aimed at repeating backcrosses at least ten times with the pollen of the same plasmon recipients. Usually two plants were used as the female in each backcross.

Field test. Various characters of the eu- and alloplasmic lines were investigated using plants grown in the field during the 1992 - 1993 winter crop season. Plots were arranged in a split plot design, in which 12 nuclei (plasmon recipients $) \times 4$ replications formed the major plots, each of which contained 47 subplots corresponding to the individual plasmons. Two plants of the same line were placed in each subplot.

Estimation of pollen fertility. Pollen fertility was determined using the field-grown materials. About 300 500 pollen grains from one ear per line were observed with no replication. Pollen grains squeezed out from several anthers just before dehiscence were stained with dilute acetocarmine then warmed with an alcohol lamp until the starch granules had mostly disappeared due to hydrolysis. The number and shapes of the nuclei in the grain were observed. Each pollen grain was classified into one of five classes: 0 , no nucleus; 1 , one nucleus; 2 , one vegetative and one generative nucleus; 3 , one vegetative and two round male nuclei; and 4, one vegetative and two wedge-shaped male nuclei. Class 4 pollen was considered fertile, and the percentage of it present in all the pollen grains was used to indicate pollen fertility.

Estimation of seed fertilities. Backcrossed (with normal pollen) and selfed seed fertilities were estimated for all the eu- and alloplasmic lines. The seed fertility (= seed setting rate in percentage) was estimated for each ear using a fraction of the number of seeds set in the normally developed or hand-pollinated first and second florets vs the total number of those florets. When more than one ear was observed in a plant, the average was taken as representing the fertility of the plant.

For backcrossed seed fertility, records of the five latest backcross generations were compiled. Backcrossings were made with greenhouse-grown plants under a long day condition (ca. 17-h light). In general, the backcrosses used 20 to 26 florets per ear, two ears per plant, and two plants per line in each generation. Selfed seed fertility was estimated for both the greenhouse-grown plants un- der the artificial long-day condition and the field-grown plants under natural conditions in Kyoto $\left(36^{\circ} \mathrm{N}\right)$. For the greenhouse-grown plants, two ears from each of two plants per line were bagged before anthesis. The seed setting rate for each ear was observed, and the average calculated for five generations. For the field-grown plants, two ears from each of two plants also were used in each replication and were observed as for the greenhouse-grown plants. The average for the two plants, used to represent the subplot value of each line, was subjected to statistical analyses after converting to the angle (Snedecor, 1955)

Fertility spectrum. The pollen or seed fertility (backcrossed as well as self-pollinated) of a set of 12 alloplasmics (genotypes Tve to Mch) with a common plasmon were depicted as a histogram. This is called a fertility spectrum.

\section{RESULTS}

\section{Problems encountered in the production of alloplasmics}

Gametocidal genes. A gametocidal gene is selfish, killing both its non-carriers, the female and male gametes that are free of it. This gene is effective in hemi- or heterozygotes but non-effective in the homozygote (Endo, 1990, for review). The extent of killing depends upon the genotype of the plant. In certain genotypes, all the female and male gametes of the non-carrier are killed, and the gene shows $100 \%$ transmission to the offspring through both gametes. In other genotypes, various percentages of the non-carrier gametes survive and participate in fertilization.

Gametocidal genes have been reported in Ae. caudata (Endo and Katayama, 1978), Ae. triuncialis (Endo and Tsunewaki, 1975), Ae. cylindrica (Endo, 1979), Ae. longissima (Maan, 1975b), Ae. sharonensis (Miller et al., 1982), and Ae. speltoides (Tsujimoto and Tsunewaki, 1984a). The gene of Ae. speltoides was transferred to wheat chromosome 2B (Tsujimoto and Tsunewaki, 1984a). The gene of all the other species is present on the donor's chromosome added to the wheat genome. Apparently, three Aegilops genomes, C, S, and S1, have gametocidal genes, but most of those Aegilops species are suspected to be dimorphic for the carrier and non-carrier. For example, in Ae. speltoides, two accessions, spl1 and spl2, were the carrier, and two other accessions, spl3 and $s p l 4$ appeared to be the non-carrier. Similarly, the $c d t 2$ of $A e$. caudata was the carrier, whereas $c d t 1$ was the non-carrier.

Due to preferential transmission, the gametocidal gene is retained in the alloplasmics through repeated backcrosses in the form of an alien chromosome addition in the cases of the genes in the $\mathrm{C}$ and $\mathrm{S}^{1}$ genomes (Endo and Tsunewaki, 1975; Maan, 1975b) or as a Mendelian factor 
in two cases of Ae. speltoides gene (Tsujimoto and Tsunewaki, 1985, 1988).

The persistence of gametocidal genes caused two serious problems in the production of alloplasmic wheats: One is a great reduction in crossed seed fertility, usually to one half (when integrated into a wheat chromosome) or one fourth (for an alien chromosome addition) of the normal seed-setting rate. This makes production and maintenance of the alloplasmics difficult. The second problem is that production of alloplasmics without the gametocidal gene or chromosome becomes very difficult, if not impossible. The genetic effect of an alloplasmon therefore becomes inseparable from that of the coexisting gametocidal chromosome.

Past records for the backcrossed and selfed seed fertilities confirm that among our plasmon donors $c d t 2$, spl1, $s p l 2, s h r, \operatorname{lng}, \operatorname{trn} 1$, and $c y l$, had a gametocidal gene(s). We discovered a very effective suppressor, $\operatorname{Igc1}$, in N26 for the gametocidal gene of $c d t 2$ and $\operatorname{trn} 1$ (Tsujimoto and Tsunewaki, 1985). Using this suppressor, the gametocidal gene could be eliminated from all the alloplasmics with these plasmons (Fig. 1). Our search for a similar suppressor of other gametocidal genes so far has been unsuccessful. Fortunately, the genes of $s p l 1, s h r$, and $c y l$ eventually were spontaneously eliminated from most of the alloplasmics during repeated backcrosses. The genes of $s p l 2$ and $\operatorname{lng}$, however, are retained in all but one alloplasmic line, causing severe female sterility (Table 3). The spl2 gene, designated $G c 1 a$, was integrated into wheat chromosome $2 \mathrm{~B}$ and now behaves as a normal Mendelian factor (Tsujimoto and Tsunewaki, 1984a, 1985), whereas the lng gene is on an intact lng chromosome added to the wheat genome. The exceptional

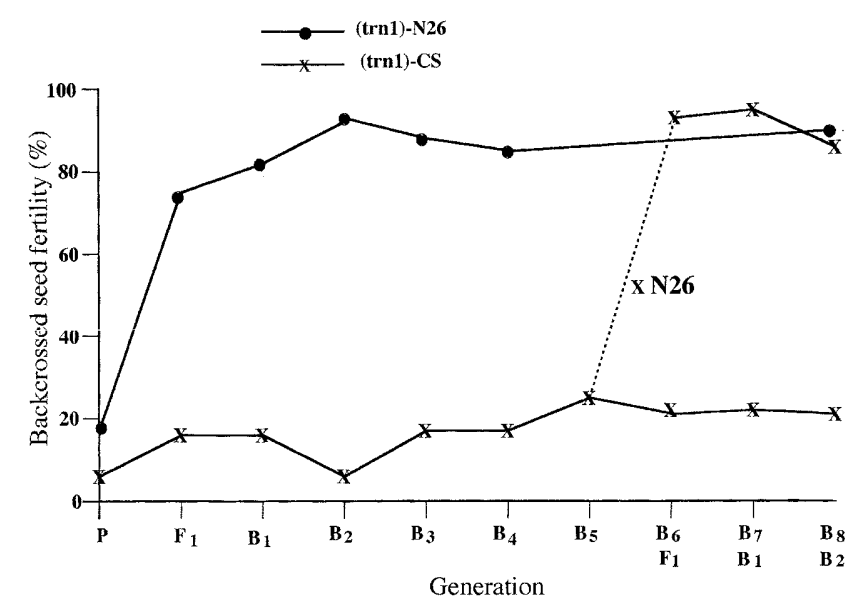

Fig. 1. Elimination of the Ae. triuncialis-derived gametocidal gene in the alloplasmic wheat, (trn1)-CS, using its suppressor, Igc1, in another common wheat, Norin 26: Female fertility, given by the backcrossed seed fertility of ( $\operatorname{trn} 1)$-CS, remained about $20 \%$ for eight backcross generations, whereas it returned to the normal level in one generation in the crossing to Norin 26. alloplasmics are (spl2)-CS and (lng)-JF, both of which have spontaneously lost the gametocidal gene and recovered normal female fertility.

Parthenogenesis. Slm, one of the 12 alloplasmon recipients, has a 1BL-1RS translocation chromosome that consists of the long arm of wheat chromosome $1 \mathrm{~B}$ and the short arm of rye chromosome 1R. The 1RS arm carries a parthenogenesis-inducing gene, $P t g$, whereas its suppressor, Spg, is located on the short arm of the normal 1B chromosome (Kobayashi and Tsunewaki, 1980a; Tsunewaki and Mukai, 1990). All the plasmons belonging to the $\mathrm{C}$, $\mathrm{C}^{2}, \mathrm{~N}, \mathrm{~S}^{1}, \mathrm{~S}^{12}, \mathrm{~S}^{\mathrm{v}}, \mathrm{T}, \mathrm{T}^{2}, \mathrm{U}$, and $\mathrm{U}^{2}$ types have a plasmagene(s) that interacts with Ptg, inducing parthenogenetic development of the egg cell to form a haploid embryo (Tsunewaki and Mukai, 1990). Of course, fertilization of the polar nuclei is necessary to produce a mature seed.

When one of the above plasmons is introduced into SIm via the alloplasmic line of another wheat that carries the normal $1 \mathrm{~B}$ chromosome, the $1 \mathrm{~B} / 1 \mathrm{BL}-1 \mathrm{RS}$ heterozygote is produced. This heterozygote forms two types of egg cell, one carrying $1 \mathrm{~B}$, the other the 1BL-1RS chromosome. The 1BL-1RS-carrying egg cell develops into a haploid embryo, whereas the 1B-carrier produces a diploid embryo that becomes the same heterozygote as the female parent, upon pollination with Slm's pollen. Thus, the 1B chromosome is preferentially transmitted to the offspring through the female gamete in 1B/1BL-1RS heterozygotes that have a parthenogenesis-inducing plasmon. This makes it difficult to produce a 1BL-1RS homozygote of alloplasmic Slm that has a parthenogenesis-inducing plasmon. Of eight haploid-producing alloplasmics of Slm that were recently studied by the C-banding technique, $(u \mathrm{mb})-,(\mathrm{clm})$-, and (unr)-Slm in the $\mathrm{B}_{17}, \mathrm{~B}_{14}$, and $\mathrm{B}_{12}$ generation, respectively retained a $1 \mathrm{~B}$ chromosome in the heterozygous state (Endo, T. R., personal commun.).

Mistagging. Mistagging of a plant or line occurred five times during the entire backcrossing program. Two were mistagging of Ae. ventricosa and Ae. longissima plasmons. In these cases, mistagging occurred when the source stock of the alloplasmic lines was received from foreign institutions. After many years of work these plasmons respectively proved to be of a G (probably T. timopheevi) and a B (T. aestivum) type. Mistagging of the vnt plasmon was found before any results were published, because we had another vnt plasmon introduced from our own source. As for the lng plasmon, its mistagging became apparent in 1984 when organellar DNAs of the alloplasmic lines with this plasmon were compared with those of native Ae. longissima accessions by restriction endonuclease analysis. The lng plasmon reported in our papers of 1981 1983 , e. g. Tsunewaki and Ogihara (1983), was the mistagged ast plasmon. The other two cases occurred in 
Table 3. Backcross generations and seed setting rates (\%) of the $s p l 2$ and $l n g$ alloplasmics pollinated with normal pollen

\begin{tabular}{|c|c|c|c|c|c|c|c|c|c|c|c|c|c|c|}
\hline $\begin{array}{l}\text { Plas- } \\
\text { mon }\end{array}$ & $\begin{array}{l}\text { Gener. } \\
\text { \& seed } \\
\operatorname{set}(\%)\end{array}$ & Tve & $\begin{array}{l}--- \\
\text { P168 }\end{array}$ & CS & $\begin{array}{r}--- \\
\mathrm{N} 26\end{array}$ & Slm & $\begin{array}{c}\mathrm{Nuc} \\
\mathrm{JF}\end{array}$ & $\begin{array}{c}\operatorname{ar} \text { ger } \\
\text { Sk }\end{array}$ & $\begin{array}{l}\text { type } \\
\quad \text { S615 }\end{array}$ & Sphr & Cmp & Splt & Mch & $\begin{array}{l}\overline{---} \\
\text { Av. }\end{array}$ \\
\hline spl2 & $\begin{array}{c}\text { Gener. } \\
\%\end{array}$ & $\begin{array}{l}\mathrm{B}_{11} \\
28\end{array}$ & $\begin{array}{l}\mathrm{B}_{11} \\
28\end{array}$ & $\begin{array}{l}\mathrm{B}_{14} \\
91\end{array}$ & $\begin{array}{l}\mathrm{B}_{12} \\
30\end{array}$ & $\begin{array}{l}\mathrm{B}_{12} \\
58\end{array}$ & $\begin{array}{l}\mathrm{B}_{12} \\
40\end{array}$ & $\begin{array}{l}\mathrm{B}_{12} \\
31\end{array}$ & $\begin{array}{l}\mathrm{B}_{13} \\
27\end{array}$ & $\begin{array}{l}\mathrm{B}_{12} \\
19\end{array}$ & $\begin{array}{l}\mathrm{B}_{11} \\
40\end{array}$ & $\begin{array}{c}\mathrm{B}_{11} \\
19\end{array}$ & $\begin{array}{c}\mathrm{B}_{10} \\
9\end{array}$ & $\begin{array}{c}- \\
30\end{array}$ \\
\hline $\operatorname{lng}$ & $\begin{array}{c}\text { Gener. } \\
\%\end{array}$ & $\begin{array}{l}\mathrm{B}_{9} \\
10\end{array}$ & $\begin{array}{c}\mathrm{B}_{8} \\
8\end{array}$ & $\begin{array}{l}\mathrm{B}_{9} \\
15\end{array}$ & $\begin{array}{l}\mathrm{B}_{8} \\
23\end{array}$ & $\begin{array}{l}\mathrm{B}_{7} \\
18\end{array}$ & $\begin{array}{l}\mathrm{B}_{9} \\
86\end{array}$ & $\begin{array}{l}\mathrm{B}_{8} \\
27\end{array}$ & $\begin{array}{l}\mathrm{B}_{6} \\
15\end{array}$ & $\begin{array}{l}\mathrm{B}_{8} \\
18\end{array}$ & $\begin{array}{l}\mathrm{B}_{8} \\
15\end{array}$ & $\begin{array}{l}\mathrm{B}_{9} \\
12\end{array}$ & $\begin{array}{l}\mathrm{B}_{3} \\
16\end{array}$ & $\begin{array}{l}- \\
22\end{array}$ \\
\hline
\end{tabular}

Note: CS and JF were excluded respectively from the calculation of the average seed setting rate of the $s p l 2$ and $l n g$ alloplasmics, because they are assumed to be the non-carrier of the gametocidal gene.

(vnt)-Slm and (vvl)-S615, both mistaggings being confirmed in the $\mathrm{B}_{7}$ generation. The former (code E36) was found to be (bnc2)-Slm (code E37), and the latter (code H56) to be (trr3)-S615 (code H57). These mistakes occurred when one extra generation was grown in North Dakota, USA in 1977 to accelerate the backcrossing program. The fifth case occurred in three alloplasmic lines with the cms plasmon in common. This case is discussed in the "Discussion".

\section{Production of $\mathbf{1 2}$ sets of the alloplasmics}

All the alloplasmic lines have been backcrossed repeatedly with the 12 common wheats as the recurrent pollen parents, and now most of them have reached $B_{10}$ or a subsequent backcross generation. Table 4 shows the present backcross generations of all the alloplasmics.

By summer, 1996, 532 of the 552 alloplasmic lines (12 genotypes $\times 46$ alloplasmons), i. e. $96.4 \%$ of all the alloplasmics, had reached the $\mathrm{B}_{10}$ or a later backcross generation. Of the remaining 20 lines, 15 have reached the $B_{7}-B_{9}$ generation and 5 are at the $B_{4}-B_{6}$ generation. The highest backcross generation reached has been $B_{46}$ of (cdt1)-Tve. Fig, 2 shows the CS's set of eu- and 46 alloplasmics. Totally, 12 such sets were produced.

\section{Fertilities of the alloplasmics}

Pollen fertility. Table 5 shows the pollen fertility, i. e., the percentage of class 4 pollen grains in all the eu- and alloplasmic lines. The averages of all plasmons belonging to the same type also are given in this table, with the standard deviation (S.D.). Thirty-one plasmons of the types $A, A^{2}, C, C^{2}, G, G^{2}, M, M^{\mathrm{h}}, M^{\circ}, N, S^{1}, S^{12}, S^{v}, T, T^{2}, U$, and $\mathrm{U}^{2}$ caused pollen sterility of $80 \%$ or higher in 1 to 12 genotypes. In these cases, interaction between the genome and plasmon clearly determines pollen sterility. The other 16 plasmons of the $\mathrm{B}, \mathrm{D}, \mathrm{D}^{2}, \mathrm{~S}$, and $\mathrm{S}^{\mathrm{b}}$ types gave high fertility to all 12 genotypes.

The developmental stage at which the most pollen grains were found in the anther just before pollen shedding is given in Table 6, in which plasmons of the same type are grouped. Clearly, pollen development in highly male-sterile lines, even with the same plasmon but differ- ent genotypes, was arrested at different stages. Normal pollen (class 4) was the major class in all the highly fertile lines.

Backcrossed seed fertility. The backcrossed seed fertilities of all the lines are given in Table 7. The average of all the plasmons belonging to the same type also is given together with the standard deviation (S.D.). This is a reasonable parameter of female fertility because normal pollen grains were used in pollination. Some underestimation, however, is assumed because of artificial pollination.

Among the 552 alloplasmics, this seed fertility varied from $3.5 \%$ in (btc)-N26 to $96.3 \%$ in (umb)-CS, the overall average being $63.5 \%$. Analysis of variance indicated the lng plasmon (average, 23.5\%) belonged to the lowest, btc $(32.3 \%)$, and spl2 $(33.0 \%)$ plasmons to the second lowest group, and mnc (46.5\%), cdt2 (47.6\%), and shr (48.1\%) plasmons to a lower group than the rest, in the averages of the 12 genotypes. No clear difference was found for the 40 remaining plasmons, whose fertilities ranged from $53.4 \%$ to $75.0 \%$. The partial female sterilities in two alloplasmics that have the spl2 and $l n g$ plasmons were due, at least in part, to gametocidal genes derived from the donors of these plasmons, whereas those caused by the btc, $m n c$, and $s h r$ plasmons were ascribable to the weakness side effect caused by these plasmons.

Selfed seed fertility of the greenhouse-grown plants. Table 8 gives the average selfed seed fertilities for the five latest generations of all the eu- and alloplasmic lines grown in a greenhouse. The average of all the plasmons belonging to the same type also is given together with the standard deviation (S.D.). The averaged fertility for the 12 genotypes varied from $0.0 \%$ for the btc and hld plasmons to $92.1 \%$ for the ast 1 plasmon. Plasmons which resembled each other in their effects on the selfed seed fertility of the 12 wheat genotypes were grouped into 14 types of fertility spectrum, the averages of which are shown by solid bars in Fig. 3, the names of the individual plasmons belonging to each spectrum also being given. The spectra had the following characteristics: 
Table 4. Backcross generations of all the alloplasmic lines obtained by summer, 1996

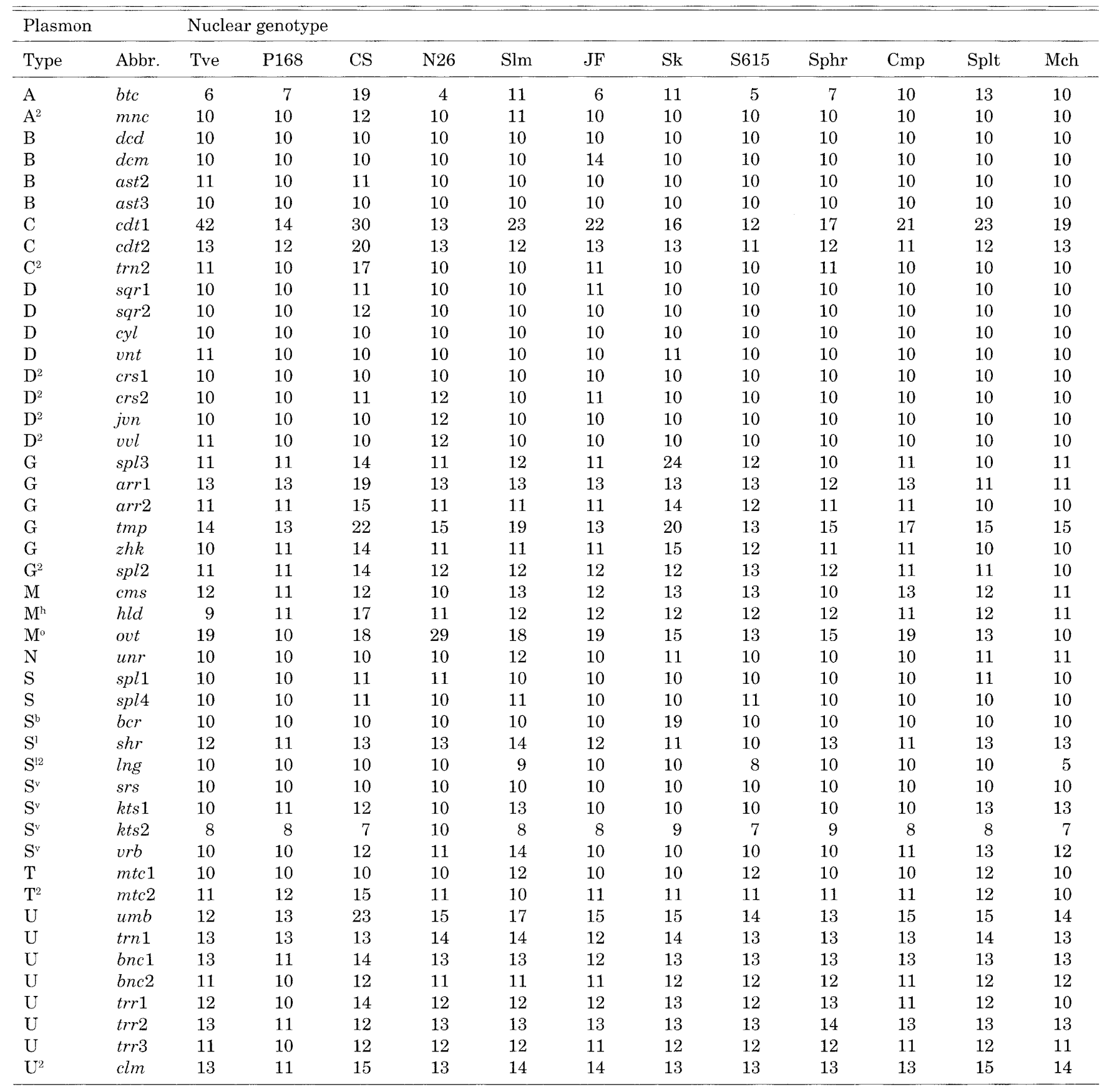

Type I: All 12 genotypes had normal fertility, though that of Shpr was slightly decreased. Twelve plasmons of the $\mathrm{B}, \mathrm{D}, \mathrm{S}$, and $\mathrm{S}^{\mathrm{b}}$ types showed this spectrum.

Type I': N26 showed severe sterility, whereas all other genotypes were normal. This spectrum therefore is treated as a subtype of type I. All four $D^{2}$ type plasmons showed this spectrum.

Type II: Three genotypes, Slm, Splt, and Mch, showed complete or nearly complete sterility, whereas the other nine had fertilities higher than 60\%. Six plasmons of the N, $\mathrm{S}^{\mathrm{v}}$, and T types gave this spectrum. Type III: Four genotypes, N26, Slm, Splt, and Mch, showed complete or nearly complete sterility. Tve, P168, and Sphr also showed sterility, each having less than $40 \%$ fertility. Five other genotypes had almost normal fertility. A single plasmon of the $\mathrm{S}^{\mathrm{l}}$ type gave this spectrum.

Type III': Tve, Slm, Splt, and Mch showed complete or nearly complete sterility. All the other genotypes, except JF, showed very severe sterility, fertility being 


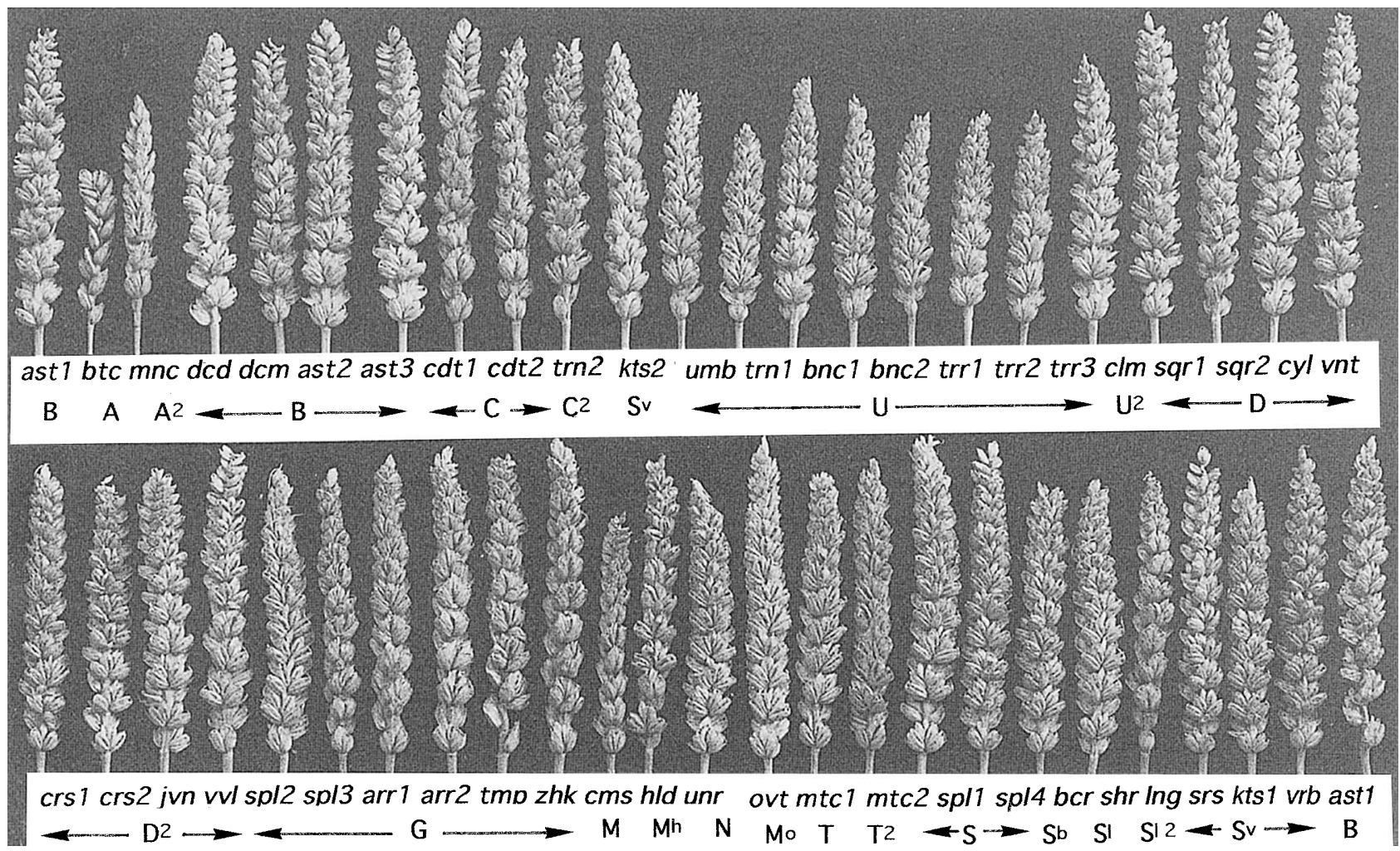

Fig. 2. Ears of the euplasmic (ast1) and 46 alloplasmics of Chinese Spring wheat, one of the 12 sets of common wheat alloplasmics produced to study the entire spectrum of plasmon diversity among Triticum and Aegilops species. Each line is indicated by its plasmon (abbreviation) and plasmon type.

Table 5. Pollen fertility (\%) of the eu- and alloplasmic lines, as the proportion of class 4 pollen

\begin{tabular}{|c|c|c|c|c|c|c|c|c|c|c|c|c|c|c|}
\hline \multicolumn{2}{|c|}{ Plasmon } & \multicolumn{13}{|c|}{ Nuclear genotype } \\
\hline Type & Abbr. & Tve & P168 & $\mathrm{CS}$ & N26 & Slm & $\mathrm{JF}$ & $\mathrm{Sk}$ & S615 & Sphr & $\mathrm{Cmp}$ & Splt & Mch & Ave. \\
\hline $\mathrm{A}$ & $b t c$ & 0 & 0 & 0 & 0 & 0 & 0 & 0 & 0 & 0 & 0 & 0 & 0 & 0 \\
\hline $\mathrm{A}^{2}$ & $m n c$ & 0 & 0 & 97 & 0 & 0 & 0 & 0 & 0 & 0 & 0 & 0 & 0 & 8 \\
\hline M & $\mathrm{cms}$ & 0 & 0 & 23 & 0 & 1 & 0 & 0 & 60 & 0 & 0 & 0 & 0 & 7 \\
\hline $\mathrm{M}^{\mathrm{h}}$ & hld & 0 & 0 & 1 & 0 & 0 & 0 & 0 & 0 & 0 & 0 & 0 & 0 & 0 \\
\hline $\mathrm{M}^{0}$ & ovt & 7 & 95 & 99 & 4 & 0 & 0 & 0 & 0 & 0 & 18 & 1 & 90 & 26 \\
\hline $\mathrm{N}$ & $u n r$ & 90 & 86 & 99 & 95 & 65 & 98 & 97 & 92 & 94 & 97 & 88 & 20 & 85 \\
\hline $\mathrm{S}^{\mathrm{b}}$ & $b c r$ & 94 & 81 & 99 & 95 & 96 & 98 & 99 & 95 & 98 & 94 & 97 & 91 & 95 \\
\hline $\mathrm{S}^{1}$ & $s h r$ & 61 & 87 & 99 & 97 & 0 & 96 & 97 & 77 & 92 & 81 & 79 & 2 & 72 \\
\hline $\mathrm{S}^{12}$ & $\operatorname{lng}$ & 76 & 36 & 87 & 75 & 43 & 97 & 80 & 74 & 66 & 63 & 14 & 0 & 59 \\
\hline $\mathrm{T}$ & $m t c 1$ & 88 & 99 & 100 & 96 & 0 & 99 & 97 & 71 & 98 & 94 & 9 & 79 & 78 \\
\hline $\mathrm{T}^{2}$ & $m t c 2$ & 0 & 0 & 0 & 0 & 0 & 0 & 0 & 0 & 0 & 0 & 0 & 26 & 2 \\
\hline B & $d c d$ & 89 & 84 & 98 & 97 & 95 & 98 & 99 & 88 & 99 & 99 & 98 & 99 & 95 \\
\hline B & $d c m$ & 89 & 96 & 97 & 97 & 95 & 99 & 98 & 85 & 97 & 98 & 97 & 95 & 95 \\
\hline B & ast 1 & 95 & 87 & 99 & 98 & 96 & 97 & 98 & 95 & 96 & 98 & 99 & 98 & 96 \\
\hline B & ast2 & 94 & 92 & 99 & 94 & 97 & 98 & 99 & 90 & 94 & 99 & 99 & 97 & 96 \\
\hline B & ast 3 & 94 & 99 & 100 & 97 & 96 & 98 & 96 & 96 & 97 & 95 & 99 & 98 & 97 \\
\hline \multirow[t]{2}{*}{ B } & Aver. & 92 & 92 & 98 & 96 & 96 & 98 & 98 & 91 & 97 & 98 & 98 & 97 & 96 \\
\hline & \pm S.D. & \pm 3 & \pm 6 & \pm 1 & \pm 2 & \pm 1 & \pm 1 & \pm 1 & \pm 5 & \pm 2 & \pm 2 & \pm 1 & \pm 2 & \pm 1 \\
\hline $\mathrm{C}$ & $c d t 1$ & 12 & 74 & 0 & 14 & 0 & 2 & 0 & 78 & 3 & 74 & 0 & 0 & 21 \\
\hline $\mathrm{C}$ & $c d t 2$ & 1 & 77 & 83 & 71 & 0 & 0 & 0 & 78 & 1 & 96 & 1 & 3 & 34 \\
\hline \multirow[t]{2}{*}{$\mathrm{C}$} & Aver. & 6 & 76 & 41 & 42 & 0 & 1 & 0 & 78 & 2 & 85 & 1 & 2 & 28 \\
\hline & \pm S.D. & \pm 8 & \pm 2 & \pm 59 & \pm 40 & \pm 0 & \pm 2 & \pm 0 & \pm 0 & \pm 1 & \pm 16 & \pm 1 & \pm 2 & \pm 9 \\
\hline $\mathrm{C}^{2}$ & $\operatorname{trn} 2$ & 96 & 88 & 52 & 50 & 0 & 1 & 0 & 82 & 2 & 95 & 96 & 95 & 55 \\
\hline
\end{tabular}

(Continued on the following page.) 


\begin{tabular}{|c|c|c|c|c|c|c|c|c|c|c|c|c|c|c|}
\hline D & $s q r 1$ & 85 & 77 & 98 & 97 & 96 & 97 & 98 & 94 & 98 & 95 & 97 & 99 & 94 \\
\hline D & sqr2 & 96 & 81 & 99 & 96 & 94 & 95 & 98 & 95 & 98 & 98 & 99 & 97 & 96 \\
\hline $\mathrm{D}$ & $c y l$ & 98 & 93 & 99 & 98 & 95 & 99 & 98 & 84 & 98 & 97 & 98 & 99 & 96 \\
\hline $\mathrm{D}$ & vnt & 95 & 89 & 99 & 99 & 96 & 97 & 98 & 96 & 97 & 95 & 98 & 99 & 97 \\
\hline \multirow[t]{2}{*}{$\mathrm{D}$} & Aver. & 94 & 85 & 99 & 98 & 95 & 97 & 98 & 92 & 98 & 96 & 98 & 99 & 96 \\
\hline & \pm S.D. & \pm 6 & \pm 7 & \pm 1 & \pm 1 & \pm 1 & \pm 2 & \pm 0 & \pm 6 & \pm 1 & \pm 2 & \pm 1 & \pm 1 & \pm 1 \\
\hline $\mathrm{D}^{2}$ & crs 1 & 88 & 88 & 99 & 91 & 68 & 96 & 98 & 97 & 92 & 98 & 98 & 99 & 93 \\
\hline $\mathrm{D}^{2}$ & crs2 & 94 & 78 & 98 & 79 & 94 & 98 & 97 & 93 & 89 & 97 & 96 & 98 & 93 \\
\hline $\mathrm{D}^{2}$ & jun & 99 & 90 & 99 & 88 & 89 & 99 & 99 & 95 & 84 & 95 & 97 & 96 & 94 \\
\hline $\mathrm{D}^{2}$ & vol & 94 & 75 & 100 & 91 & 93 & 96 & 97 & 96 & 99 & 98 & 99 & 99 & 95 \\
\hline \multirow[t]{2}{*}{$\mathrm{D}^{2}$} & Aver. & 94 & 83 & 99 & 87 & 86 & 97 & 98 & 95 & 91 & 97 & 98 & 98 & 94 \\
\hline & \pm S.D. & \pm 5 & \pm 7 & \pm 1 & \pm 6 & \pm 12 & \pm 2 & \pm 1 & \pm 2 & \pm 6 & \pm 1 & \pm 1 & \pm 1 & \pm 1 \\
\hline $\mathrm{G}$ & spl3 & 0 & 0 & 12 & 0 & 0 & 0 & 0 & 0 & 0 & 0 & 96 & 98 & 17 \\
\hline G & arr 1 & 0 & 0 & 3 & 1 & 0 & 0 & 0 & 0 & 0 & 0 & 94 & 93 & 16 \\
\hline G & $\operatorname{arr} 2$ & 1 & 0 & 0 & 0 & 0 & 0 & 0 & 0 & 0 & 0 & 93 & 95 & 16 \\
\hline $\mathrm{G}$ & $t m p$ & 0 & 0 & 44 & 0 & 0 & 0 & 0 & 0 & 0 & 0 & 96 & 96 & 20 \\
\hline G & $z h k$ & 0 & 0 & 2 & 1 & 0 & 0 & 2 & 0 & 0 & 0 & 97 & 96 & 17 \\
\hline \multirow[t]{2}{*}{ G } & Aver. & 0 & 0 & 12 & 1 & 0 & 0 & 1 & 0 & 0 & 0 & 95 & 96 & 17 \\
\hline & \pm S.D. & \pm 0 & \pm 0 & \pm 18 & \pm 1 & \pm 0 & \pm 0 & \pm 0 & \pm 0 & \pm 0 & \pm 0 & \pm 2 & \pm 2 & \pm 2 \\
\hline $\mathrm{G}^{2}$ & spl2 & 0 & 0 & 95 & 0 & 0 & 0 & 71 & 0 & 0 & 93 & 77 & 97 & 36 \\
\hline S & spl1 & 90 & 90 & 97 & 86 & 94 & 99 & 99 & 88 & 99 & 95 & 98 & 86 & 93 \\
\hline $\mathrm{S}$ & spl4 & 92 & 82 & 97 & 98 & 96 & 97 & 99 & 97 & 99 & 96 & 97 & 98 & 96 \\
\hline \multirow[t]{2}{*}{$\mathrm{S}$} & Aver. & 91 & 86 & 97 & 92 & 95 & 98 & 99 & 93 & 99 & 96 & 98 & 92 & 95 \\
\hline & \pm S.D. & \pm 1 & \pm 6 & \pm 0 & \pm 9 & \pm 1 & \pm 1 & \pm 0 & \pm 6 & \pm 0 & \pm 1 & \pm 1 & \pm 9 & \pm 2 \\
\hline $\mathrm{S}^{\mathrm{v}}$ & $s r s$ & 87 & 90 & 99 & 97 & 8 & 97 & 98 & 96 & 93 & 96 & 0 & 45 & 76 \\
\hline $\mathrm{S}^{\mathrm{v}}$ & $k t s 1$ & 84 & 87 & 99 & 99 & 73 & 98 & 98 & 79 & 96 & 97 & 21 & 8 & 78 \\
\hline $\mathrm{S}^{\mathrm{v}}$ & kts 2 & 95 & 89 & 97 & 98 & 0 & 98 & 100 & 97 & 98 & 98 & 13 & 0 & 74 \\
\hline $\mathrm{S}^{\mathrm{v}}$ & vrb & 96 & 83 & 99 & 98 & 3 & 98 & 98 & 97 & 97 & 98 & 12 & 0 & 73 \\
\hline \multirow[t]{2}{*}{$\mathrm{S}^{\mathrm{v}}$} & Aver. & 90 & 88 & 99 & 98 & 21 & 98 & 98 & 92 & 96 & 97 & 11 & 13 & 75 \\
\hline & \pm S.D. & \pm 6 & \pm 3 & \pm 1 & \pm 1 & \pm 35 & \pm 1 & \pm 1 & \pm 9 & \pm 2 & \pm 1 & \pm 8 & \pm 21 & \pm 2 \\
\hline $\mathrm{U}$ & $u m b$ & 0 & 78 & 92 & 91 & 0 & 98 & 9 & 49 & 50 & 70 & 32 & 0 & 47 \\
\hline $\mathrm{U}$ & $\operatorname{trn} 1$ & 0 & 71 & 98 & 92 & 0 & 96 & 89 & 30 & 69 & 67 & 9 & 0 & 52 \\
\hline $\mathrm{U}$ & $b n c 1$ & 2 & 83 & 99 & 93 & 0 & 97 & 2 & 75 & 4 & 72 & 0 & 3 & 44 \\
\hline $\mathrm{U}$ & bnc 2 & 0 & 82 & 95 & 85 & 0 & 98 & 0 & 62 & 0 & 71 & 0 & 0 & 41 \\
\hline $\mathrm{U}$ & $\operatorname{trr} 1$ & 9 & 84 & 100 & 92 & 0 & 92 & 17 & 79 & 43 & 70 & 0 & 0 & 49 \\
\hline $\mathrm{U}$ & $\operatorname{trr} 2$ & 2 & 84 & 100 & 87 & 0 & 93 & 7 & 83 & 71 & 26 & 1 & 0 & 54 \\
\hline $\mathrm{U}$ & $\operatorname{trr} 3$ & 0 & 85 & 100 & 83 & 1 & 91 & 9 & 22 & 3 & 85 & 0 & 0 & 40 \\
\hline \multirow[t]{2}{*}{$\mathrm{U}$} & Aver. & 2 & 81 & 98 & 89 & 0 & 95 & 19 & 57 & 34 & 66 & 6 & 0 & 46 \\
\hline & \pm S.D. & \pm 3 & \pm 5 & \pm 3 & \pm 4 & \pm 0 & \pm 3 & \pm 31 & \pm 24 & \pm 32 & \pm 19 & \pm 12 & \pm 1 & \pm 6 \\
\hline $\mathrm{U}^{2}$ & $\mathrm{clm}$ & 0 & 83 & 95 & 72 & 0 & 0 & 0 & 0 & 2 & 13 & 0 & 8 & 23 \\
\hline \multicolumn{2}{|c|}{ Overall ave. } & 49 & 64 & 78 & 66 & 36 & 64 & 54 & 61 & 54 & 66 & 53 & 55 & 58 \\
\hline
\end{tabular}

The average and standard deviation also are shown for each plasmon type in which more than one plasmon was studied.

$30 \%$ or lower. A single plasmon of the $\mathrm{S}^{12}$ type gave this spectrum.

Type IV: Eight genotypes, Tve, N26, Slm, Sk, S615, Sphr, Splt, and Mch, showed complete or nearly complete sterility. P168, JF, and Cmp had fertilities of less than $40 \%$. CS alone had normal fertility. All seven plasmons of the U type gave this spectrum.

Type IV': All the genotypes, except P168 and CS, showed complete or almost complete sterility. This spectrum, however, resembles Type IV and therefore is treated as its subtype. A single plasmon of the $\mathrm{U}^{2}$ type gave this spectrum.

Type V: All the genotypes, except Tve, P168, S615, and Cmp, showed complete or nearly complete sterility.
The fertility of Cmp was almost normal. The major difference from spectrum VIII was the ca. $30 \%$ fertility of Tve in this type, whereas it was completely sterile in spectrum VIII. A single plasmon of the $\mathrm{C}^{2}$ type gave this spectrum.

Type VI: P168 and CS showed normal fertility, whereas Mch had only ca. $20 \%$ fertility. All the other genotypes were completely sterile. A single plasmon of the $\mathrm{M}^{\circ}$ type gave this spectrum.

Type VII: Splt and Mch showed normal fertility, whereas all the other genotypes were completely sterile. All five plasmons of the $\mathrm{G}$ type gave this spectrum.

Type VII': CS and Mch showed 40 - 60\% fertility, and Splt only $10 \%$ fertility. All the other genotypes were com- 
Table 6. Developmental stage in which a majority of pollen grains were present just before sheddinga)

\begin{tabular}{|c|c|c|c|c|c|c|c|c|c|c|c|c|c|}
\hline $\begin{array}{l}\text { Plas- } \\
\text { mon } \\
\text { type }\end{array}$ & $\begin{array}{l}\text { No. } \\
\text { plas- } \\
\text { mons }\end{array}$ & $\begin{array}{c}\text { Nucl } \\
\text { Tve }\end{array}$ & $\begin{array}{c}\text { genotyp } \\
--- \\
\text { P168 }\end{array}$ & $\mathrm{CS}$ & N26 & $\begin{array}{c}--- \\
\text { Slm }\end{array}$ & $\mathrm{JF}$ & $\mathrm{Sk}$ & $\begin{array}{l}--- \\
\text { S615 }\end{array}$ & $\begin{array}{l} \\
\text { Sphr }\end{array}$ & $\mathrm{Cmp}$ & $\begin{array}{c}--- \\
\text { Splt }\end{array}$ & Mch \\
\hline A & 1 & -\# & -\# & $0 \#$ & -\# & 0\# & -\# & -\# & -\# & $0 \#$ & -\# & O\# & 0\# \\
\hline $\mathrm{A}^{2}$ & 1 & $0 \#$ & 0\# & $\mathrm{N}$ & -\# & $0 \#$ & $0 \#$ & -\# & $0 \#$ & $0 \#$ & 0\# & 0\# & 0\# \\
\hline B & 5 & $\mathrm{~N}$ & $\mathrm{~N}$ & $\mathrm{~N}$ & $\mathrm{~N}$ & $\mathrm{~N}$ & $\mathrm{~N}$ & $\mathrm{~N}$ & $\mathrm{~N}$ & $\mathrm{~N}$ & $\mathrm{~N}$ & $\mathrm{~N}$ & $\mathrm{~N}$ \\
\hline $\mathrm{C}$ & 2 & $2 \#$ & $\mathrm{~N}$ & $0 \#$ & $0 \#$ & 0\# & $0 \#$ & 0\# & $\mathrm{N}$ & $0 \#$ & $\mathrm{~N}$ & $2 \#$ & $2 \#$ \\
\hline $\mathrm{C}^{2}$ & 1 & $\mathrm{~N}$ & $\mathrm{~N}$ & N\# & -\# & 0\# & $0 \#$ & 0\# & $\mathrm{N}$ & $0 \#$ & $\mathrm{~N}$ & $\mathrm{~N}$ & $\mathrm{~N}$ \\
\hline $\mathrm{D}$ & 4 & $\mathrm{~N}$ & $\mathrm{~N}$ & $\mathrm{~N}$ & $\mathrm{~N}$ & $\mathrm{~N}$ & $\mathrm{~N}$ & $\mathrm{~N}$ & $\mathrm{~N}$ & $\mathrm{~N}$ & $\mathrm{~N}$ & $\mathrm{~N}$ & $\mathrm{~N}$ \\
\hline $\mathrm{D}^{2}$ & 4 & $\mathrm{~N}$ & $\mathrm{~N}$ & $\mathrm{~N}$ & $\mathrm{~N}$ & $\mathrm{~N}$ & $\mathrm{~N}$ & $\mathrm{~N}$ & $\mathrm{~N}$ & $\mathrm{~N}$ & $\mathrm{~N}$ & $\mathrm{~N}$ & $\mathrm{~N}$ \\
\hline $\mathrm{G}$ & 5 & $1 \#$ & $1 \#$ & $1 \#$ & $2 \#$ & $0 \#$ & $0 \#$ & $1 \#$ & $1 \#$ & $2 \#$ & $2 \#$ & $\mathrm{~N}$ & $\mathrm{~N}$ \\
\hline $\mathrm{G}^{2}$ & 1 & $1 \#$ & $1 \#$ & $\mathrm{~N}$ & $2 \#$ & -\# & -\# & N\# & $1 \#$ & -\# & N\# & N\# & $\mathrm{N}$ \\
\hline M & 1 & $1 \#$ & $0 \#$ & $1 \#$ & -\# & 0\# & -\# & -\# & N\# & 0\# & -\# & 0\# & -\# \\
\hline $\mathrm{M}^{\mathrm{h}}$ & 1 & $0 \#$ & $-\#$ & $0 \#$ & $-\#$ & 0\# & -\# & -\# & -\# & 0\# & -\# & $0 \#$ & -\# \\
\hline $\mathrm{M}^{\circ}$ & 1 & $2 \#$ & $\mathrm{~N}$ & $\mathrm{~N}$ & $2 \#$ & $0 \#$ & $0 \#$ & $1 \#$ & 0\# & $2 \#$ & $2 \#$ & $3 \#$ & $\mathrm{~N}$ \\
\hline $\mathrm{N}$ & 1 & $\mathrm{~N}$ & $\mathrm{~N}$ & $\mathrm{~N}$ & $\mathrm{~N}$ & N\# & $\mathrm{N}$ & $\mathrm{N}$ & $\mathrm{N}$ & $\mathrm{N}$ & $\mathrm{N}$ & N\# & $2 \#$ \\
\hline $\mathrm{S}$ & 2 & $\mathrm{~N}$ & $\mathrm{~N}$ & $\mathrm{~N}$ & $\mathrm{~N}$ & $\mathrm{~N}$ & $\mathrm{~N}$ & $\mathrm{~N}$ & $\mathrm{~N}$ & $\mathrm{~N}$ & $\mathrm{~N}$ & $\mathrm{~N}$ & $\mathrm{~N}$ \\
\hline $\mathrm{S}^{\mathrm{b}}$ & 1 & $\mathrm{~N}$ & $\mathrm{~N}$ & $\mathrm{~N}$ & $\mathrm{~N}$ & $\mathrm{~N}$ & $\mathrm{~N}$ & $\mathrm{~N}$ & $\mathrm{~N}$ & $\mathrm{~N}$ & $\mathrm{~N}$ & $\mathrm{~N}$ & $\mathrm{~N}$ \\
\hline $\mathrm{S}^{1}$ & 1 & $\mathrm{~N}$ & $\mathrm{~N}$ & $\mathrm{~N}$ & $\mathrm{N \#}$ & $1 \#$ & $\mathrm{~N}$ & $\mathrm{~N}$ & $\mathrm{~N}$ & $\mathrm{~N}$ & $\mathrm{~N}$ & $\mathrm{N \#}$ & $2 \#$ \\
\hline $\mathrm{S}^{12}$ & 1 & $\mathrm{N \#}$ & $\mathrm{N}$ & $\mathrm{N \#}$ & N\# & $\mathrm{N} \#$ & $\mathrm{~N}$ & $\mathrm{N \#}$ & $\mathrm{N \#}$ & $\mathrm{N} \#$ & N\# & $3 \#$ & -\# \\
\hline $\mathrm{S}^{v}$ & 4 & $\mathrm{~N}$ & $\mathrm{~N}$ & $\mathrm{~N}$ & $\mathrm{~N}$ & $3 \#$ & $\mathrm{~N}$ & $\mathrm{~N}$ & $\mathrm{~N}$ & $\mathrm{~N}$ & $\mathrm{~N}$ & $3 \#$ & $3 \#$ \\
\hline $\mathrm{T}$ & 1 & $\mathrm{~N}$ & $\mathrm{~N}$ & $\mathrm{~N}$ & $\mathrm{~N}$ & $2 \#$ & $\mathrm{~N}$ & $\mathrm{~N}$ & $\mathrm{~N}$ & $\mathrm{~N}$ & $\mathrm{~N}$ & 0\# & N\# \\
\hline $\mathrm{T}^{2}$ & 1 & 0\# & 0\# & $1 \#$ & $2 \#$ & $0 \#$ & $2 \#$ & $1 \#$ & 0\# & $2 \#$ & $2 \#$ & $1 \#$ & $2 \#$ \\
\hline $\mathrm{U}$ & 7 & $2 \#$ & $\mathrm{~N}$ & $\mathrm{~N}$ & $\mathrm{N \#}$ & 0\# & $\mathrm{N}$ & $1 \#$ & N\# & $2 \#$ & $\mathrm{~N}$ & $1 \#$ & $2 \#$ \\
\hline $\mathrm{U}^{2}$ & 1 & 0\# & $\mathrm{N}$ & $\mathrm{N}$ & N\# & $0 \#$ & $0 \#$ & $1 \#$ & $0 \#$ & $0 \#$ & $\mathrm{~N}$ & $1 \#$ & $1 \#$ \\
\hline
\end{tabular}

Plasmons are grouped by type.

a) -, no pollen (degenerated anthers); 0 , no nucleus; 1 , uninucleate; 2 , binucleate; 3 , aberrant trinucleate with two round male nuclei;

$\mathrm{N}$, normal trinucleate.

\#) Highly sterile genome-plasmon combination $(<20 \%$ selfed seed fertility).

Table 7. Average backcrossed seed fertility $(\%)$ of the alloplasmic lines in the five most advanced generations grown in a greenhouse

\begin{tabular}{|c|c|c|c|c|c|c|c|c|c|c|c|c|c|c|}
\hline \multicolumn{2}{|c|}{ Plasmon } & \multicolumn{13}{|c|}{ Nuclear genotype } \\
\hline Type & Abbr. & Tve & P168 & $\mathrm{CS}$ & N26 & Slm & $\mathrm{JF}$ & $\mathrm{Sk}$ & $\mathrm{S} 615$ & Sphr & Cmp & Splt & Mch & Ave. \\
\hline $\mathrm{A}$ & $b t c$ & 43 & 51 & 54 & 4 & 59 & 10 & 30 & 25 & 10 & 46 & 33 & 23 & 32 \\
\hline $\mathrm{A}^{2}$ & $m n c$ & 46 & 47 & 50 & 17 & 69 & 63 & 42 & 46 & 38 & 53 & 47 & 40 & 47 \\
\hline M & $\mathrm{cms}$ & 57 & 56 & 91 & 53 & 79 & 58 & 67 & 80 & 50 & 76 & 41 & 50 & 63 \\
\hline $\mathrm{M}^{\mathrm{h}}$ & hld & 73 & 55 & 93 & 43 & 76 & 51 & 59 & 79 & 43 & 81 & 66 & 61 & 65 \\
\hline $\mathrm{M}^{\mathrm{o}}$ & ovt & 80 & 58 & 95 & 68 & 87 & 91 & 71 & 67 & 67 & 89 & 65 & 58 & 75 \\
\hline $\mathrm{N}$ & $u n r$ & 63 & 75 & 88 & 82 & 50 & 76 & 76 & 70 & 51 & 83 & 60 & 33 & 67 \\
\hline $\mathrm{S}^{\mathrm{b}}$ & $b c r$ & 74 & 80 & 84 & 74 & 82 & 73 & 59 & 69 & 57 & 86 & 56 & 51 & 70 \\
\hline $\mathbf{S}^{1}$ & $\operatorname{sh} r$ & 26 & 26 & 86 & 25 & 37 & 50 & 47 & 77 & 60 & 64 & 31 & 48 & 48 \\
\hline $\mathrm{S}^{12}$ & $\operatorname{lng}$ & 21 & 18 & 17 & 23 & 18 & 69 & 22 & 20 & 16 & 18 & 15 & 24 & 24 \\
\hline $\mathrm{T}$ & $m t c 1$ & 63 & 70 & 83 & 77 & 53 & 82 & 79 & 69 & 49 & 80 & 51 & 54 & 68 \\
\hline $\mathrm{T}^{2}$ & $m t c 2$ & 79 & 70 & 94 & 78 & 61 & 75 & 71 & 78 & 45 & 81 & 73 & 41 & 71 \\
\hline $\mathrm{B}$ & $d c d$ & 72 & 83 & 90 & 83 & 82 & 77 & 72 & 75 & 55 & 76 & 59 & 50 & 73 \\
\hline B & $\mathrm{dcm}$ & 77 & 74 & 93 & 77 & 70 & 75 & 86 & 80 & 34 & 58 & 83 & 68 & 73 \\
\hline B & ast 2 & 70 & 74 & 83 & 58 & 69 & 76 & 65 & 85 & 60 & 72 & 73 & 49 & 70 \\
\hline B & ast 3 & 79 & 58 & 92 & 84 & 87 & 78 & 68 & 77 & 53 & 81 & 70 & 40 & 72 \\
\hline \multirow[t]{2}{*}{ B } & Aver. & 75 & 72 & 90 & 75 & 77 & 76 & 73 & 79 & 51 & 72 & 71 & 52 & 72 \\
\hline & \pm S.D. & \pm 4 & \pm 11 & \pm 4 & \pm 12 & \pm 9 & \pm 1 & \pm 9 & \pm 4 & \pm 11 & \pm 10 & \pm 10 & \pm 12 & \pm 2 \\
\hline $\mathrm{C}$ & $c d t 1$ & 68 & 64 & 80 & 37 & 61 & 41 & 56 & 66 & 39 & 87 & 28 & 41 & 56 \\
\hline $\mathrm{C}$ & $c d t 2$ & 56 & 72 & 83 & 47 & 48 & 40 & 36 & 57 & 3 & 78 & 17 & 33 & 48 \\
\hline \multirow[t]{2}{*}{$\mathrm{C}$} & Aver. & 62 & 68 & 82 & 42 & 55 & 40 & 46 & 62 & 21 & 83 & 22 & 37 & 52 \\
\hline & \pm S.D. & \pm 9 & \pm 6 & \pm 3 & \pm 7 & \pm 9 & \pm 1 & \pm 14 & \pm 7 & \pm 25 & \pm 6 & \pm 8 & \pm 6 & \pm 6 \\
\hline $\mathrm{C}^{2}$ & $\operatorname{trn} 2$ & 66 & 61 & 85 & 47 & 76 & 64 & 44 & 58 & 33 & 81 & 44 & 46 & 59 \\
\hline $\mathrm{D}$ & $s q r 1$ & 68 & 70 & 88 & 64 & 72 & 81 & 80 & 81 & 59 & 84 & 79 & 62 & 74 \\
\hline
\end{tabular}

(Continued on the following page.) 
Production and fertility of alloplasmic wheats

\begin{tabular}{|c|c|c|c|c|c|c|c|c|c|c|c|c|c|c|}
\hline $\mathrm{D}$ & $s q r 2$ & 72 & 63 & 92 & 84 & 83 & 77 & 74 & 71 & 56 & 83 & 61 & 55 & 73 \\
\hline $\mathrm{D}$ & $c y l$ & 62 & 76 & 91. & 71 & 78 & 42 & 78 & 72 & 69 & 88 & 82 & 51 & 72 \\
\hline $\mathrm{D}$ & vnt & 74 & 79 & 90 & 55 & 83 & 83 & 78 & 80 & 61 & 79 & 65 & 61 & \\
\hline \multirow[t]{2}{*}{ D } & Aver. & 69 & 72 & 90 & 68 & 79 & 71 & 77 & 76 & 61 & 84 & 72 & 57 & $r$ \\
\hline & \pm S.D. & \pm 6 & \pm 7 & \pm 2 & \pm 12 & \pm 5 & \pm 19 & \pm 3 & \pm 5 & \pm 6 & \pm 4 & \pm 10 & \pm 5 & \\
\hline $\mathrm{D}^{2}$ & $\operatorname{crs} 1$ & 71 & 68 & 85 & 58 & 80 & 57 & 75 & 58 & 36 & 85 & 60 & 48 & \\
\hline$D^{2}$ & crs 2 & 59 & 62 & 92 & 57 & 63 & 87 & 61 & 73 & 57 & 78 & 78 & 41 & \\
\hline $\mathrm{D}^{2}$ & jon & 56 & 61 & 95 & 61 & 69 & 87 & 63 & 72 & 46 & 82 & 76 & 45 & \\
\hline $\mathrm{D}^{2}$ & vol & 69 & 69 & 92 & 68 & 71 & 74 & 68 & 69 & 63 & 78 & 74 & 46 & \\
\hline \multirow[t]{2}{*}{$\mathrm{D}^{2}$} & Aver. & 64 & 65 & 91 & 61 & 71 & 76 & 66 & 68 & 51 & 81 & 72 & 45 & \\
\hline & \pm S.D. & \pm 7 & \pm 4 & \pm 4 & \pm 5 & \pm 7 & \pm 14 & \pm 6 & \pm 7 & \pm 12 & \pm 4 & \pm 8 & \pm 3 & \pm \\
\hline G & $s p l 3$ & 64 & 73 & 62 & 70 & 76 & 68 & 59 & 69 & 51 & 75 & 66 & 43 & \\
\hline G & arr 1 & 64 & 74 & 72 & 78 & 83 & 79 & 70 & 81 & 65 & 82 & 70 & 39 & \\
\hline G & arr2 & 65 & 75 & 66 & 75 & 81 & 79 & 69 & 72 & 44 & 78 & 55 & 54 & \\
\hline G & $t m p$ & 65 & 72 & 73 & 71 & 89 & 79 & 62 & 71 & 59 & 85 & 83 & 77 & \\
\hline G & $z h k$ & 64 & 74 & 72 & 78 & 83 & 79 & 70 & 81 & 65 & 82 & 70 & 39 & \\
\hline \multirow[t]{2}{*}{$\mathrm{G}$} & Aver. & 66 & 74 & 68 & 70 & 82 & 75 & 64 & 74 & 53 & 78 & 67 & 54 & \\
\hline & \pm S.D. & \pm 3 & \pm 2 & \pm 5 & \pm 8 & \pm 5 & \pm 6 & \pm 5 & \pm 5 & \pm 9 & \pm 6 & \pm 11 & \pm 15 & \\
\hline $\mathrm{G}^{2}$ & spl2 & 29 & 32 & 56 & 37 & 43 & 35 & 27 & 33 & 32 & 43 & 20 & 10 & \\
\hline $\mathrm{S}$ & spl 1 & 78 & 76 & 92 & 76 & 76 & 91 & 74 & 80 & 64 & 66 & 59 & 69 & \\
\hline $\mathrm{S}$ & spl4 & 64 & 67 & 91 & 81 & 70 & 87 & 48 & 74 & 56 & 86 & 56 & 44 & \\
\hline \multirow[t]{2}{*}{$\mathrm{S}$} & Aver. & 71 & 72 & 92 & 79 & 73 & 89 & 61 & 77 & 60 & 76 & 58 & 56 & \\
\hline & \pm S.D. & \pm 10 & \pm 6 & \pm 1 & \pm 4 & \pm 4 & \pm 3 & \pm 18 & \pm 4 & \pm 5 & \pm 14 & \pm 2 & \pm 17 & \\
\hline $\mathrm{S}^{\mathrm{v}}$ & srs & 73 & 67 & 93 & 88 & 55 & 88 & 77 & 76 & 56 & 89 & 61 & 58 & \\
\hline$S^{v}$ & $k t s 1$ & 69 & 84 & 83 & 56 & 64 & 84 & 77 & 80 & 56 & 87 & 60 & 68 & \\
\hline$S^{v}$ & $k t s 2$ & 76 & 66 & 94 & 76 & 51 & 84 & 78 & 65 & 61 & 82 & 69 & 50 & \\
\hline$S^{v}$ & vrb & 74 & 71 & 81 & 81 & 59 & 79 & 82 & 79 & 62 & 64 & 60 & 63 & \\
\hline \multirow[t]{2}{*}{$\mathrm{S}^{\mathrm{v}}$} & Aver. & 73 & 72 & 88 & 75 & 57 & 84 & 79 & 75 & 59 & 81 & 62 & 60 & \\
\hline & \pm S.D. & \pm 3 & \pm 8 & \pm 7 & \pm 14 & \pm 6 & \pm 4 & \pm 2 & \pm 7 & \pm 3 & \pm 11 & \pm 5 & \pm 8 & $\perp$ \\
\hline $\mathrm{U}$ & $u m b$ & 53 & 71 & 96 & 50 & 52 & 73 & 66 & 72 & 58 & 93 & 32 & 22 & \\
\hline $\mathrm{U}$ & $\operatorname{trn} 1$ & 61 & 69 & 84 & 53 & 30 & 73 & 71 & 62 & 64 & 79 & 22 & 41 & \\
\hline $\mathrm{U}$ & bnc 1 & 32 & 73 & 90 & 66 & 40 & 85 & 58 & 63 & 52 & 70 & 35 & 47 & \\
\hline $\mathrm{U}$ & bnc 2 & 47 & 69 & 86 & 54 & 38 & 86 & 66 & 55 & 40 & 75 & 34 & 48 & \\
\hline $\mathrm{U}$ & $\operatorname{trr} 1$ & 31 & 68 & 75 & 57 & 50 & 73 & 73 & 71 & 41 & 69 & 6 & 28 & \\
\hline $\mathrm{U}$ & $\operatorname{trr} 2$ & 39 & 59 & 78 & 49 & 52 & 80 & 58 & 75 & 42 & 78 & 43 & 33 & \\
\hline $\mathrm{U}$ & $\operatorname{trr} 3$ & 43 & 77 & 88 & 54 & 54 & 79 & 72 & 60 & 48 & 85 & 33 & 38 & \\
\hline \multirow[t]{2}{*}{$\mathrm{U}$} & Aver. & 44 & 69 & 85 & 55 & 45 & 78 & 66 & 66 & 49 & 78 & 29 & 37 & \\
\hline & \pm S.D. & \pm 11 & \pm 6 & \pm 7 & \pm 6 & \pm 9 & \pm 6 & \pm 6 & \pm 7 & \pm 9 & \pm 9 & \pm 12 & \pm 10 & \\
\hline $\mathrm{U}^{2}$ & $\mathrm{clm}$ & 60 & 59 & 68 & 65 & 50 & 77 & 66 & 81 & 49 & 82 & 30 & 56 & \\
\hline
\end{tabular}

Overall ave.

$61 \quad 66$

Table 8. Average selfed seed fertility $(\%)$ of the eu- and alloplasmic lines in the five most advanced generations grown in a greenhouse

\begin{tabular}{|c|c|c|c|c|c|c|c|c|c|c|c|c|c|c|}
\hline \multicolumn{2}{|c|}{ Plasmon } & \multicolumn{13}{|c|}{ Nuclear genotype } \\
\hline Type & Abbr. & Tve & P168 & $\mathrm{CS}$ & N26 & $\operatorname{SIm}$ & $\mathrm{JF}$ & Sk & $\mathrm{S} 615$ & Sphr & $\mathrm{Cmp}$ & Splt & Mch & Ave. \\
\hline A & btc & 0 & 0 & 0 & 0 & 0 & 0 & 0 & 0 & 0 & 0 & 0 & 0 & 0 \\
\hline$A^{2}$ & $m n c$ & 0 & 0 & 4 & 0 & 0 & 0 & 0 & 0 & 0 & 0 & 0 & 0 & 0 \\
\hline M & $\mathrm{cms}$ & 0 & 0 & 0 & 0 & 0 & 0 & 0 & 0 & 0 & 0 & 0 & 0 & 0 \\
\hline $\mathbf{M}^{\mathrm{h}}$ & hld & 0 & 0 & 0 & 0 & 0 & 0 & 0 & 0 & 0 & 0 & 0 & 0 & 0 \\
\hline $\mathrm{M}^{0}$ & ovt & 0 & 82 & 57 & 0 & 0 & 0 & 0 & 0 & 0 & 0 & 0 & 16 & 13 \\
\hline $\mathrm{N}$ & unr & 64 & 81 & 95 & 92 & 15 & 91 & 89 & 88 & 82 & 81 & 0 & 4 & 65 \\
\hline $\mathrm{S}^{\mathrm{b}}$ & $b c r$ & 85 & 83 & 98 & 88 & 71 & 81 & 85 & 80 & 55 & 84 & 75 & 89 & 81 \\
\hline $\mathrm{S}^{1}$ & $\operatorname{sh} r$ & 35 & 37 & 79 & 8 & 0 & 52 & 63 & 78 & 35 & 74 & 1 & 0 & 39 \\
\hline $\mathrm{S}^{12}$ & $\operatorname{lng}$ & 7 & 19 & 27 & 20 & 0 & 75 & 20 & 34 & 13 & 9 & 3 & 0 & 19 \\
\hline $\mathrm{T}$ & $m t c 1$ & 22 & 67 & 94 & 59 & 0 & 72 & 85 & 11 & 61 & 62 & 0 & 0 & 44 \\
\hline $\mathrm{T}^{2}$ & $m t c 2$ & 0 & 0 & 1 & 0 & 0 & 0 & 0 & 0 & 0 & 0 & 0 & 0 & 0 \\
\hline B & $d c d$ & 85 & 90 & 99 & 95 & 87 & 95 & 91 & 93 & 82 & 88 & 82 & 86 & 89 \\
\hline
\end{tabular}

(Continued on the following page.) 
K. TSUNEWAKI et al.

\begin{tabular}{|c|c|c|c|c|c|c|c|c|c|c|c|c|c|c|}
\hline B & dcm & 88 & 90 & 98 & 98 & 87 & 96 & 88 & 92 & 81 & 87 & 89 & 81 & 90 \\
\hline B & ast 1 & 90 & 92 & 96 & 98 & 95 & 97 & 90 & 95 & 82 & 89 & 90 & 92 & 92 \\
\hline B & ast 2 & 80 & 88 & 98 & 93 & 89 & 91 & 88 & 92 & 78 & 77 & 81 & 86 & 87 \\
\hline B & ast 3 & 88 & 88 & 96 & 87 & 84 & 98 & 90 & 90 & 75 & 87 & 89 & 94 & 89 \\
\hline \multirow[t]{2}{*}{ B } & Aver. & 86 & 90 & 98 & 94 & 89 & 95 & 89 & 92 & 80 & 85 & 86 & 88 & 89 \\
\hline & \pm S.D. & \pm 4 & \pm 2 & \pm 1 & \pm 5 & \pm 4 & \pm 3 & \pm 1 & \pm 2 & \pm 3 & \pm 5 & \pm 5 & \pm 5 & \pm 2 \\
\hline $\mathrm{C}$ & $c d t 1$ & 0 & 36 & 0 & 0 & 0 & 0 & 0 & 31 & 0 & 75 & 0 & 0 & 12 \\
\hline C & $c d t 2$ & 0 & 20 & 0 & 0 & 0 & 0 & 0 & 2 & 0 & 74 & 0 & 0 & 8 \\
\hline \multirow[t]{2}{*}{$\mathrm{C}$} & Aver. & 0 & 28 & 0 & 0 & 0 & 0 & 0 & 17 & 0 & 74 & 0 & 0 & 10 \\
\hline & \pm S.D. & \pm 0 & \pm 11 & \pm 0 & \pm 0 & \pm 0 & \pm 0 & \pm 0 & \pm 21 & \pm 0 & \pm 1 & \pm 0 & \pm 0 & \pm 3 \\
\hline $\mathrm{C}^{2}$ & $\operatorname{trn} 2$ & 29 & 35 & 0 & 0 & 0 & 0 & 0 & 12 & 0 & 59 & 2 & 5 & 12 \\
\hline $\mathrm{D}$ & $s q r 1$ & 86 & 90 & 98 & 93 & 84 & 92 & 90 & 94 & 81 & 92 & 82 & 82 & 89 \\
\hline $\mathrm{D}$ & $s q r 2$ & 84 & 88 & 94 & 92 & 95 & 95 & 86 & 89 & 68 & 76 & 88 & 92 & 87 \\
\hline $\mathrm{D}$ & cyl & 88 & 92 & 97 & 95 & 77 & 94 & 88 & 90 & 81 & 85 & 87 & 89 & 88 \\
\hline $\mathrm{D}$ & vnt & 90 & 87 & 96 & 97 & 90 & 90 & 88 & 91 & 79 & 90 & 82 & 84 & 89 \\
\hline \multirow[t]{2}{*}{$\mathrm{D}$} & Aver. & 87 & 89 & 96 & 94 & 86 & 93 & 88 & 91 & 77 & 86 & 85 & 87 & 88 \\
\hline & \pm S.D. & \pm 2 & \pm 2 & \pm 2 & \pm 3 & \pm 8 & \pm 2 & \pm 1 & \pm 2 & \pm 6 & \pm 7 & \pm 3 & \pm 5 & \pm 1 \\
\hline $\mathrm{D}^{2}$ & crs 1 & 80 & 78 & 96 & 11 & 68 & 70 & 88 & 82 & 53 & 60 & 63 & 80 & 69 \\
\hline $\mathrm{D}^{2}$ & $c r s 2$ & 80 & 88 & 95 & 31 & 79 & 84 & 89 & 90 & 51 & 85 & 82 & 84 & 78 \\
\hline $\mathrm{D}^{2}$ & jun & 82 & 79 & 97 & 37 & 68 & 84 & 88 & 87 & 57 & 82 & 79 & 85 & 77 \\
\hline $\mathrm{D}^{2}$ & $v v l$ & 84 & 92 & 97 & 40 & 80 & 63 & 88 & 73 & 86 & 64 & 88 & 81 & 78 \\
\hline \multirow[t]{2}{*}{$\mathrm{D}^{2}$} & Aver. & 82 & 84 & 96 & 30 & 74 & 75 & 88 & 83 & 62 & 73 & 78 & 83 & 76 \\
\hline & \pm S.D. & \pm 2 & \pm 7 & \pm 1 & \pm 13 & \pm 7 & \pm 11 & \pm 1 & \pm 8 & \pm 17 & \pm 13 & \pm 11 & \pm 2 & \pm 4 \\
\hline $\mathrm{G}$ & spl3 & 0 & 0 & 0 & 0 & 0 & 0 & 0 & 0 & 0 & 0 & 72 & 35 & 9 \\
\hline G & $\operatorname{arr} 1$ & 0 & 0 & 0 & 0 & 0 & 0 & 0 & 0 & 0 & 0 & 85 & 70 & 13 \\
\hline $\mathrm{G}$ & arr2 & 0 & 0 & 0 & 0 & 0 & 0 & 0 & 0 & 0 & 0 & 75 & 47 & 10 \\
\hline $\mathrm{G}$ & $t m p$ & 0 & 0 & 4 & 0 & 0 & 0 & 0 & 0 & 0 & 0 & 89 & 66 & 13 \\
\hline G & $z h k$ & 0 & 0 & 1 & 0 & 0 & 0 & 0 & 0 & 0 & 0 & 77 & 42 & 10 \\
\hline \multirow[t]{2}{*}{ G } & Aver. & 0 & 0 & 1 & 0 & 0 & 0 & 0 & 0 & 0 & 0 & 80 & 52 & 11 \\
\hline & \pm S.D. & \pm 0 & \pm 0 & \pm 2 & \pm 0 & \pm 0 & \pm 0 & \pm 0 & \pm 0 & \pm 0 & \pm 0 & \pm 7 & \pm 15 & \pm 2 \\
\hline $\mathrm{G}^{2}$ & spl2 & 0 & 0 & 42 & 0 & 0 & 0 & 0 & 0 & 0 & 0 & 10 & 54 & 9 \\
\hline $\mathrm{S}$ & $s p l 1$ & 86 & 91 & 96 & 95 & 50 & 86 & 77 & 90 & 84 & 66 & 87 & 80 & 82 \\
\hline$S$ & spl4 & 74 & 78 & 94 & 91 & 55 & 93 & 78 & 82 & 40 & 74 & 83 & 79 & 77 \\
\hline \multirow[t]{2}{*}{ S } & Aver. & 80 & 84 & 95 & 93 & 52 & 90 & 77 & 86 & 62 & 70 & 85 & 80 & 80 \\
\hline & \pm S.D. & \pm 8 & \pm 10 & \pm 1 & \pm 2 & \pm 4 & \pm 5 & \pm 1 & \pm 5 & \pm 32 & \pm 6 & \pm 3 & \pm 1 & \pm 4 \\
\hline$S^{v}$ & srs & 78 & 84 & 98 & 89 & 0 & 89 & 84 & 81 & 41 & 82 & 5 & 2 & 61 \\
\hline$S^{v}$ & $k t s 1$ & 65 & 91 & 96 & 93 & 5 & 90 & 89 & 80 & 74 & 79 & 0 & 0 & 64 \\
\hline$S^{v}$ & $k t s 2$ & 87 & 89 & 83 & 81 & 10 & 81 & 90 & 76 & 61 & 66 & 0 & 8 & 61 \\
\hline $\mathrm{S}^{\mathrm{v}}$ & $v r b$ & 76 & 84 & 98 & 98 & 0 & 94 & 91 & 89 & 65 & 78 & 0 & 0 & 64 \\
\hline \multirow[t]{2}{*}{$\mathrm{S}^{\mathrm{v}}$} & Aver. & 77 & 87 & 94 & 90 & 4 & 89 & 89 & 81 & 60 & 76 & 1 & 3 & 63 \\
\hline & \pm S.D. & \pm 9 & \pm 3 & \pm 7 & \pm 7 & \pm 5 & \pm 6 & \pm 3 & \pm 6 & \pm 14 & \pm 7 & \pm 2 & \pm 4 & \pm 2 \\
\hline $\mathrm{U}$ & $u m b$ & 0 & 51 & 77 & 5 & 0 & 52 & 3 & 8 & 0 & 17 & 0 & 0 & 18 \\
\hline $\mathrm{U}$ & $\operatorname{trn} 1$ & 1 & 39 & 69 & 3 & 0 & 31 & 34 & 18 & 0 & 31 & 0 & 1 & 19 \\
\hline $\mathrm{U}$ & bnc 1 & 0 & 25 & 75 & 3 & 0 & 50 & 3 & 4 & 0 & 23 & 0 & 0 & 15 \\
\hline $\mathrm{U}$ & bnc2 & 0 & 28 & 75 & 0 & 0 & 22 & 0 & 0 & 0 & 6 & 0 & 0 & 11 \\
\hline $\mathrm{U}$ & $\operatorname{trr} 1$ & 0 & 35 & 63 & 0 & 0 & 14 & 2 & 0 & 0 & 4 & 0 & 0 & 10 \\
\hline $\mathrm{U}$ & $\operatorname{trr} 2$ & 0 & 21 & 81 & 1 & 0 & 49 & 2 & 16 & 0 & 14 & 0 & 0 & 15 \\
\hline $\mathrm{U}$ & $\operatorname{trr} 3$ & 0 & 27 & 69 & 0 & 0 & 21 & 0 & 0 & 0 & 9 & 0 & 1 & 11 \\
\hline \multirow[t]{2}{*}{$\mathrm{U}$} & Aver. & 0 & 32 & 73 & 2 & 0 & 34 & 6 & 7 & 0 & 15 & 0 & 0 & 14 \\
\hline & \pm S.D. & \pm 0 & \pm 10 & \pm 6 & \pm 2 & \pm 0 & \pm 16 & \pm 12 & \pm 8 & \pm 0 & \pm 10 & \pm 0 & \pm 0 & \pm 4 \\
\hline $\mathrm{U}^{2}$ & $\mathrm{clm}$ & 0 & 30 & 45 & 3 & 0 & 3 & 1 & 0 & 0 & 6 & 0 & 0 & 7 \\
\hline \multicolumn{2}{|c|}{ Overall ave. } & 39 & 51 & 61 & 38 & 27 & 49 & 44 & 43 & 33 & 45 & 37 & 37 & 42 \\
\hline
\end{tabular}

pletely sterile. This spectrum differed from type VII in showing high fertility for CS, and very low fertility for Splt. It therefore is treated as a subtype of VII. A single plasmon of the $\mathrm{G}^{2}$ type gave this spectrum.

Type VIII: JF had normal fertility, and P168 and S615 showed moderate fertility, ca. $30 \%$. All the other genotypes were completely sterile. Both plasmons of the $\mathrm{C}$ type gave this spectrum.

Type IX: All but CS were completely sterile. CS had ca. $5 \%$ fertility. A single plasmon of the $\mathrm{A}^{2}$ type gave this spectrum.

Type X: All the genotypes had less than $1 \%$ fertility. Four 

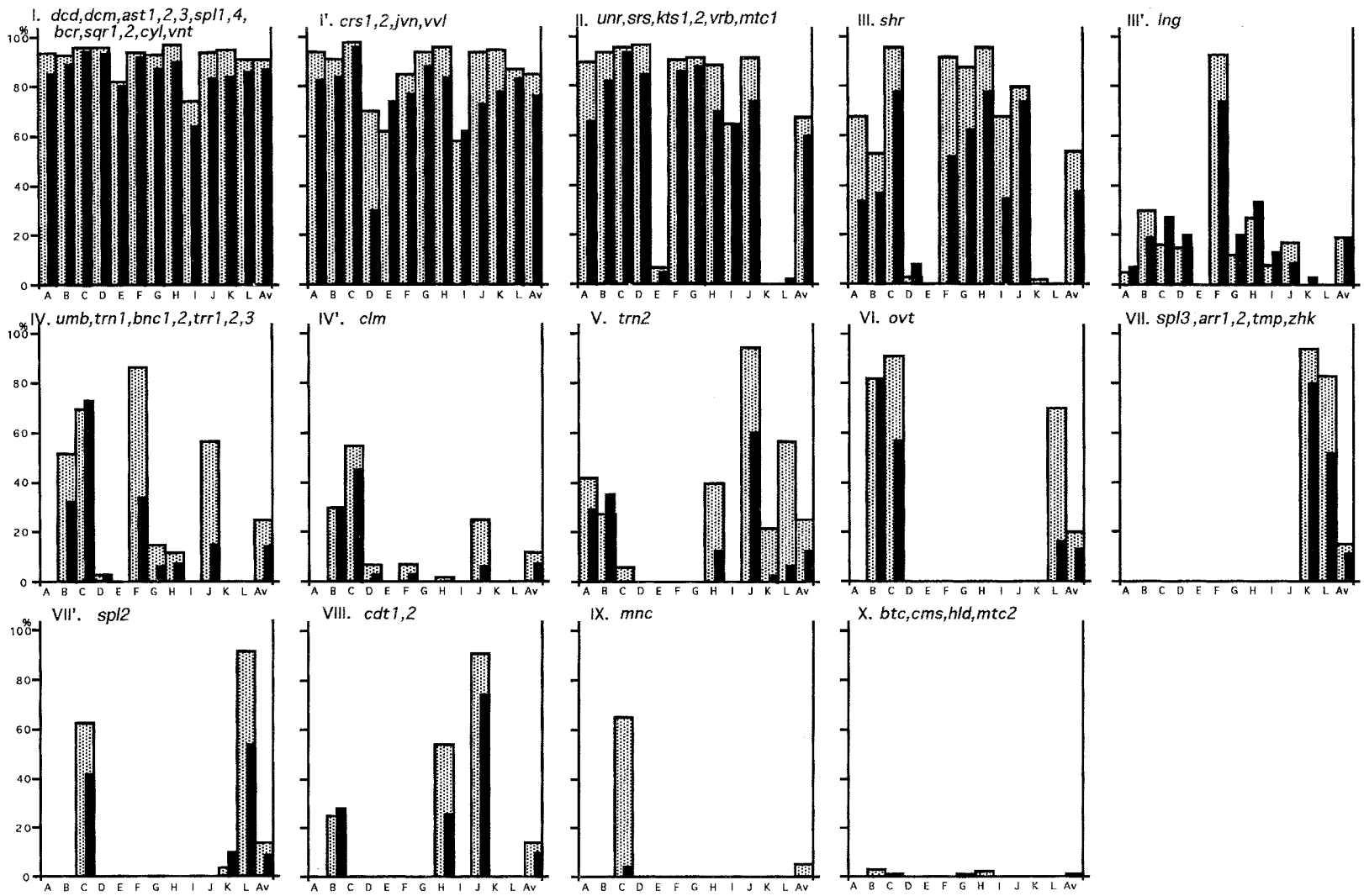

Fig. 3. Selfed seed fertility spectra of the 47 plasmons classified in ten major and four subtypes; plasmons belonging to each spectrum type are indicated at the top. Ordinate: Selfed seed fertility (\%). Abscissa: 12 wheat genotypes (A-L and average). Solid bars: Spectra of greenhouse-grown plants. Stippled bars: Spectra of field-grown plants.

Table 9. Selfed seed fertility (\%) of the eu- and alloplasmic lines grown in the field; average of four replications

\begin{tabular}{|c|c|c|c|c|c|c|c|c|c|c|c|c|c|c|}
\hline \multicolumn{2}{|c|}{ Plasmon } & \multicolumn{13}{|c|}{ Nuclear genotype } \\
\hline Type & Abbr. & Tve & P168 & $\mathrm{CS}$ & $\mathrm{N} 26$ & SIm & JF & Sk & $\mathrm{S} 615$ & Sphr & $\mathrm{Cmp}$ & Splt & Mch & Ave. \\
\hline A & $b t c$ & 0 & 0 & 1 & 0 & 0 & 0 & 0 & 0 & 0 & 0 & 0 & 0 & 0 \\
\hline $\mathrm{A}^{2}$ & $m n c$ & 0 & 0 & 65 & 0 & 0 & 0 & 0 & 0 & 0 & 0 & 0 & 0 & 5 \\
\hline M & $\mathrm{cms}$ & 0 & 0 & 0 & 0 & 0 & 0 & 2 & 7 & 0 & 0 & 0 & 0 & 1 \\
\hline $\mathrm{M}^{\mathrm{h}}$ & hld & 0 & 0 & 0 & 0 & 0 & 0 & 3 & 2 & 0 & 0 & 0 & 0 & 0 \\
\hline $\mathrm{M}^{\circ}$ & ovt & 0 & 82 & 91 & 0 & 0 & 0 & 0 & 0 & 0 & 0 & 0 & 70 & 20 \\
\hline $\mathrm{N}$ & unr & 93 & 92 & 95 & 96 & 26 & 96 & 86 & 98 & 67 & 94 & 0 & 1 & 70 \\
\hline$S^{b}$ & $b c r$ & 94 & 90 & 96 & 96 & 63 & 96 & 94 & 99 & 60 & 95 & 95 & 93 & 89 \\
\hline $\mathrm{S}^{1}$ & $\operatorname{shr}$ & 68 & 53 & 96 & 3 & 0 & 92 & 88 & 96 & 68 & 80 & 2 & 0 & 54 \\
\hline $\mathrm{S}^{12}$ & $\operatorname{lng}$ & 5 & 30 & 16 & 15 & 0 & 93 & 12 & 27 & 8 & 17 & 0 & 0 & 19 \\
\hline $\mathrm{T}$ & $m t c 1$ & 83 & 91 & 95 & 94 & 2 & 68 & 89 & 46 & 70 & 89 & 0 & 0 & 61 \\
\hline $\mathrm{T}^{2}$ & $m t c 2$ & 0 & 12 & 1 & 0 & 0 & 0 & 0 & 0 & 0 & 0 & 0 & 1 & 1 \\
\hline B & $d c d$ & 95 & 94 & 96 & 95 & 85 & 94 & 95 & 96 & 73 & 94 & 95 & 87 & 92 \\
\hline B & $\mathrm{dcm}$ & 92 & 93 & 96 & 94 & 88 & 95 & 90 & 96 & 71 & 93 & 97 & 94 & 92 \\
\hline B & ast 1 & 93 & 94 & 97 & 96 & 91 & 95 & 95 & 96 & 77 & 97 & 95 & 93 & 93 \\
\hline B & ast 2 & 94 & 96 & 98 & 97 & 89 & 94 & 93 & 97 & 75 & 89 & 97 & 91 & 93 \\
\hline$B$ & ast 3 & 96 & 95 & 97 & 96 & 87 & 96 & 94 & 97 & 75 & 93 & 98 & 95 & 93 \\
\hline \multirow[t]{2}{*}{ B } & Aver. & 94 & 94 & 97 & 95 & 88 & 95 & 94 & 96 & 74 & 93 & 96 & 92 & 92 \\
\hline & \pm S.D. & \pm 2 & \pm 1 & \pm 1 & \pm 1 & \pm 2 & \pm 1 & \pm 2 & \pm 1 & \pm 2 & \pm 3 & \pm 1 & \pm 3 & \pm 1 \\
\hline $\mathrm{C}$ & $c d t 1$ & 0 & 29 & 0 & 0 & 0 & 0 & 0 & 60 & 0 & 92 & 0 & 0 & 15 \\
\hline $\mathrm{C}$ & $c d t 2$ & 0 & 20 & 0 & 0 & 0 & 0 & 0 & 48 & 0 & 89 & 0 & 0 & 13 \\
\hline \multirow[t]{2}{*}{$\mathrm{C}$} & Aver. & 0 & 25 & 0 & 0 & 0 & 0 & 0 & 54 & 0 & 91 & 0 & 0 & 14 \\
\hline & \pm S.D. & \pm 0 & \pm 6 & \pm 0 & \pm 0 & \pm 0 & \pm 0 & \pm 0 & \pm 8 & \pm 0 & \pm 3 & \pm 0 & \pm 0 & \pm 1 \\
\hline
\end{tabular}

(Continued on the following page.) 


\begin{tabular}{|c|c|c|c|c|c|c|c|c|c|c|c|c|c|c|}
\hline $\mathrm{C}^{2}$ & $\operatorname{trn} 2$ & 41 & 27 & 5 & 0 & 0 & 0 & 0 & 39 & 0 & 94 & 20 & 56 & 24 \\
\hline $\mathrm{D}$ & $s q r 1$ & 96 & 94 & 94 & 99 & 78 & 93 & 93 & 96 & 79 & 95 & 97 & 87 & 92 \\
\hline $\mathrm{D}$ & sqr2 & 96 & 95 & 96 & 95 & 85 & 90 & 91 & 98 & 66 & 93 & 96 & 86 & 90 \\
\hline $\mathrm{D}$ & $c y l$ & 93 & 92 & 95 & 95 & 82 & 92 & 89 & 96 & 81 & 93 & 93 & 90 & 91 \\
\hline $\mathrm{D}$ & vnt & 93 & 87 & 99 & 97 & 88 & 95 & 91 & 98 & 77 & 96 & 89 & 87 & 91 \\
\hline \multirow[t]{2}{*}{$\mathrm{D}$} & Aver. & 94 & 92 & 96 & 97 & 83 & 93 & 91 & 97 & 76 & 94 & 94 & 87 & 91 \\
\hline & \pm S.D. & \pm 2 & \pm 4 & \pm 2 & \pm 2 & \pm 4 & \pm 2 & \pm 2 & \pm 1 & \pm 7 & \pm 2 & \pm 4 & \pm 2 & \pm 1 \\
\hline $\mathrm{D}^{2}$ & $\operatorname{crs} 1$ & 93 & 93 & 96 & 71 & 20 & 81 & 93 & 96 & 52 & 91 & 96 & 84 & 80 \\
\hline $\mathrm{D}^{2}$ & $c r s 2$ & 94 & 89 & 98 & 69 & 71 & 87 & 94 & 96 & 50 & 97 & 96 & 80 & 85 \\
\hline $\mathrm{D}^{2}$ & jon & 94 & 91 & 98 & 73 & 74 & 85 & 94 & 98 & 53 & 95 & 92 & 91 & 87 \\
\hline$D^{2}$ & vel & 95 & 92 & 98 & 66 & 82 & 89 & 93 & 95 & 77 & 93 & 97 & 94 & 89 \\
\hline \multirow[t]{2}{*}{$\mathrm{D}^{2}$} & Aver. & 94 & 91 & 98 & 70 & 62 & 85 & 94 & 96 & 58 & 94 & 95 & 87 & 85 \\
\hline & \pm S.D. & \pm 1 & \pm 2 & \pm 1 & \pm 3 & \pm 28 & \pm 4 & \pm 1 & \pm 1 & \pm 13 & \pm 3 & \pm 2 & \pm 7 & \pm 4 \\
\hline $\mathrm{G}$ & $s p l 3$ & 0 & 0 & 0 & 0 & 0 & 0 & 0 & 0 & 0 & 0 & 89 & 78 & 14 \\
\hline $\mathrm{G}$ & $\operatorname{arr} 1$ & 0 & 0 & 0 & 0 & 0 & 0 & 0 & 0 & 0 & 0 & 93 & 78 & 14 \\
\hline $\mathrm{G}$ & arr2 & 0 & 0 & 0 & 0 & 0 & 0 & 0 & 0 & 0 & 0 & 96 & 81 & 15 \\
\hline G & $t m p$ & 0 & 0 & 0 & 0 & 0 & 0 & 0 & 0 & 0 & 0 & 96 & 90 & 16 \\
\hline G & $z h k$ & 0 & 0 & 1 & 0 & 0 & 0 & 0 & 0 & 0 & 0 & 95 & 89 & 15 \\
\hline \multirow[t]{2}{*}{ G } & Aver. & 0 & 0 & 0 & 0 & 0 & 0 & 0 & 0 & 0 & 0 & 94 & 83 & 15 \\
\hline & \pm S.D. & \pm 0 & \pm 0 & \pm 0 & \pm 0 & \pm 0 & \pm 0 & \pm 0 & \pm 0 & \pm 0 & \pm 0 & \pm 3 & \pm 6 & \pm 1 \\
\hline $\mathrm{G}^{2}$ & $s p l 2$ & 0 & 0 & 63 & 0 & 0 & 0 & 3 & 0 & 0 & 0 & 4 & 92 & 14 \\
\hline S & $s p l 1$ & 91 & 90 & 90 & 95 & 63 & 94 & 93 & 95 & 72 & 92 & 95 & 94 & 89 \\
\hline$S$ & spl4 & 95 & 91 & 95 & 98 & 82 & 93 & 91 & 99 & 79 & 91 & 94 & 94 & 92 \\
\hline \multirow[t]{2}{*}{ S } & Aver. & 93 & 91 & 93 & 97 & 73 & 93 & 92 & 97 & 76 & 92 & 94 & 94 & 90 \\
\hline & \pm S.D. & \pm 3 & \pm 1 & \pm 3 & \pm 2 & \pm 13 & \pm 1 & \pm 2 & \pm 3 & \pm 5 & \pm 1 & \pm 1 & \pm 0 & \pm 2 \\
\hline $\mathrm{S}^{\mathrm{v}}$ & srs & 84 & 95 & 97 & 98 & 1 & 98 & 94 & 99 & 50 & 97 & 0 & 0 & 68 \\
\hline $\mathrm{S}^{\mathrm{v}}$ & $k t s 1$ & 93 & 94 & 96 & 98 & 9 & 95 & 92 & 97 & 75 & 94 & 0 & 0 & 70 \\
\hline $\mathrm{S}^{\mathrm{v}}$ & kts2 & 92 & 96 & 97 & 97 & 2 & 94 & 95 & 93 & 67 & 83 & 0 & 0 & 68 \\
\hline $\mathrm{S}^{\mathrm{v}}$ & $v r b$ & 94 & 96 & 97 & 98 & 1 & 95 & 94 & 98 & 60 & 93 & 0 & 0 & 69 \\
\hline \multirow[t]{2}{*}{$S^{v}$} & Aver. & 91 & 95 & 97 & 98 & 3 & 95 & 94 & 97 & 63 & 92 & 0 & 0 & 69 \\
\hline & \pm S.D. & \pm 5 & \pm 1 & \pm 0 & \pm 1 & \pm 4 & \pm 2 & \pm 1 & \pm 2 & \pm 11 & \pm 6 & \pm 0 & \pm 0 & \pm 1 \\
\hline $\mathrm{U}$ & $u m b$ & 0 & 48 & 74 & 1 & 1 & 82 & 13 & 27 & 0 & 29 & 1 & 0 & 23 \\
\hline $\mathrm{U}$ & $\operatorname{trn} 1$ & 0 & 61 & 76 & 3 & 0 & 91 & 44 & 13 & 0 & 72 & 0 & 0 & 30 \\
\hline $\mathrm{U}$ & bnc1 & 0 & 50 & 66 & 4 & 0 & 86 & 19 & 13 & 0 & 66 & 0 & 0 & 25 \\
\hline $\mathrm{U}$ & bnc 2 & 0 & 50 & 74 & 0 & 0 & 92 & 9 & 4 & 0 & 60 & 0 & 0 & 24 \\
\hline $\mathrm{U}$ & $\operatorname{trr} 1$ & 0 & 56 & 68 & 10 & 0 & 87 & 5 & 8 & 0 & 58 & 0 & 0 & 24 \\
\hline $\mathrm{U}$ & $\operatorname{trr} 2$ & 0 & 60 & 67 & 2 & 1 & 84 & 11 & 9 & 0 & 51 & 0 & 0 & 24 \\
\hline $\mathrm{U}$ & trr3 & 0 & 42 & 66 & 3 & 1 & 87 & 6 & 7 & 0 & 61 & 0 & 0 & 23 \\
\hline \multirow{2}{*}{$\mathrm{U}$} & Aver. & 0 & 52 & 70 & 3 & 0 & 87 & 15 & 12 & 0 & 57 & 0 & 0 & 25 \\
\hline & \pm S.D. & \pm 0 & \pm 7 & \pm 4 & \pm 3 & \pm 0 & \pm 3 & \pm 14 & \pm 7 & \pm 0 & \pm 14 & \pm 0 & \pm 0 & \pm 3 \\
\hline $\mathrm{U}^{2}$ & $\mathrm{clm}$ & 0 & 30 & 75 & 7 & 0 & 7 & 1 & 2 & 0 & 25 & 0 & 0 & 12 \\
\hline \multicolumn{2}{|c|}{ Overall ave. } & 46 & 57 & 64 & 44 & 27 & 60 & 48 & 52 & 34 & 61 & 43 & 44 & 48 \\
\hline
\end{tabular}

plasmons of the A, M, $\mathrm{M}^{\mathrm{h}}$, and $\mathrm{T}^{2}$ type gave this spectrum.

Selfed seed fertility of the field-grown plants. Table 9 lists the average selfed seed fertilities of the field-grown plants for four replications. The averages of all the plasmons belonging to the same type are given together with the standard deviation (S.D.). Analysis of variance indicated that the 47 plasmons can be classified into the following 12 distinct groups from the highly fertile to deeply sterile (fertility range given in parentheses after the group number):

Group 1 (88.8 93.2\%): ast1,2,3, dcd, dcm (B plasmon); sqr1,2, cyl, vnt (D plasmon); vvl ( $\mathrm{D}^{2}$ plasmon); spl1,4
(S plasmon); bcr ( $\mathrm{S}^{\mathrm{b}}$ plasmon)

Group 2 (85.1 86.5\%): crs2, jun ( $\mathrm{D}^{2}$ plasmon)

Group 3 (80.4\%): crs1 ( $\mathrm{D}^{2}$ plasmon)

Group 4 (67.6 70.2\%): unr (N plasmon); srs, $k t s 1,2, v r b$ ( $\mathrm{S}^{v}$ plasmon)

Group 5 (60.5\%): $m t c 1$ ( $\mathrm{T}$ plasmon)

Group 6 (53.8\%): shr ( $\mathrm{S}^{1}$ plasmon)

Group 7 (30.0\%): trn 1 (U plasmon)

Group 8 (22.8 25.3\%): trn2 (C $\mathrm{C}^{2}$ plasmon); umb, bnc 1,2 , trr1,2,3 (U plasmon)

Group 9 (18.6 20.3\%): ovt ( $\mathrm{M}^{\mathrm{o}}$ plasmon); lng ( $\mathrm{S}^{12}$ plasmon) Group 10 (12.2 15.5\%): $c d t 1,2$ (C plasmon); spl3, arr 1,2, tmp, zhk (G plasmon); spl2 ( $\mathrm{G}^{2}$ plasmon); $\operatorname{clm}\left(\mathrm{U}^{2}\right.$ plasmon)

Group 11 (5.4\%): mnc (A $\mathrm{A}^{2}$ plasmon) 
Group $12(0.1 \sim 1.2 \%)$ : btc (A plasmon); $\mathrm{cms}$ (M plasmon); hld ( $\mathrm{M}^{\mathrm{h}}$ plasmon); $m t c 2$ ( $\mathrm{T}^{2}$ plasmon)

As to the fertility spectrum drawn in Fig. 3 with the stippled bars, the 47 plasmons were grouped in the same way as the greenhouse-grown plants. Fig. 3 gives a comparison of the selfed seed fertilities of the greenhouse- and field-grown plants. Although the essential features of each spectrum type did not differ between the greenhouseand field-grown plants, the degree of fertility in the following genotype-plasmon combinations was about two-fold or higher in the latter: Tve with the $\mathrm{S}^{1}$ plasmon (spectrum III); CS with the $\mathrm{A}^{2}$ plasmon (IX); N26 with the $\mathrm{D}^{2}$ plasmons (I'); JF with the $\mathrm{S}^{\mathrm{I}}$ and U plasmons (III, and IV); S615 with the $\mathrm{C}$ and $\mathrm{C}^{2}$ plasmons (VIII, and V); Sphr with the $\mathrm{S}^{1}$ plasmon (III); Cmp with the $\mathrm{U}, \mathrm{U}^{2}$, and $\mathrm{C}^{2}$ plasmons (IV, IV', and V); and Mch with the $\mathrm{C}^{2}, \mathrm{M}^{\circ}, \mathrm{G}$, and $\mathrm{G}^{2}$ plasmons (V, VI, VII, and VII'). All these genotypeplasmon combinations show photoperiod-sensitive male sterility. No genotype-plasmon combination showed clear fertility improvement under the greenhouse conditions, as compared to the field conditions.

\section{DISCUSSION}

Problems encountered in the production of alloplasmic wheat lines. Two preferentially transmitted genetic factors, a gametocidal agent (chromosome or gene) and the $1 \mathrm{~B}$ chromosome, respectively hindered the complete recovery of the supposed wheat genotypes produced by repeated backcrosses in all the alloplasmic lines of the 12 wheats and in the alloplasmic lines of SIm with a parthenogenesis-inducing plasmon.

The discovery of an epistatic suppressor, $\operatorname{Igc} 1$, of C genome-derived gametocidal genes allowed the deletion of these genes from all the alloplasmic lines that carried them (Tsujimoto and Tsunewaki, 1985), but we were forced to restart production of these alloplasmics from the beginning. So far, we have been unsuccessful in finding suppressors to the gametocidal agents of three Sitopsis species, Ae. speltoides, Ae. sharonensis and Ae. longissima, and must wait for their spontaneous elimination from the carrier alloplasmics.

There is a complete solution for the elimination of intact 1B chromosome from parthenogenetic alloplasmic lines of Slm carrying a 1BL-1RS translocation. Haplo-diplo twin pairs are obtained at a certain frequency in the offspring of alloplasmic Slm with a parthenogenesis-inducing plasmon when pollinated with normal Slm (Kobayashi and Tsunewaki, 1980b; Tsunewaki, 1993). Of these twin pairs, diploid twins receive the $1 \mathrm{BL}-1 \mathrm{RS}$ chromosome from both the female and pollen parents, becoming translocation homozygotes (Kobayashi and Tsunewaki, 1980a). These 1BL-1RS homozygotes, however, produce haploids at very high frequency $(70-80 \%)$ (Kobayashi and
Tsunewaki, 1980a; Mukai, 1981). This gives rise to another problem; maintenance of the alloplasmics becomes difficult because of the rare occurrence of diploids. A reasonable solution to these contradictory problems is to maintain the stocks in the heterozygous state of 1B/1BL1RS, and select the 1BL-1RS homozygotes from the haplodiplo twin pairs when needed.

Many other problems occurred in the production of alloplasmic wheats. Some of those encountered in the production of alloplasmic lines with an M type plasmon are shown in Fig. 4. Ae. comosa, the carrier of the M type plasmon, first was crossed as female to emmer wheat ("AB" in Fig. 4) because of the strong hybridization barrier to common wheat, after which the $\mathbf{F}_{1}$ hybrids and their offspring were repeatedly crossed to 11 common wheats except for Mch, a carrier of $C h 1$, one of the two complementary genes for hybrid chlorosis. $\mathrm{A} \mathrm{B}_{3}$ plant of $(\mathrm{cms})$-Splt then was crossed to an experimental $6 \mathrm{x}$ line ("ch1ch2" in Fig. 4) that was free of both the $C h 1$ and $C h 2$ genes, and the offspring crossed to Mch. In the next generation normal plants that segregated among chlorotic sibs were selected for backcrossing with Mch. Later backcrosses proceeded smoothly until the $\mathrm{B}_{11}$ generation. In 1978 , three lines with this plasmon; (cms)-CS, N26 and Sphr, had normal growth, whereas all the other lines showed severe growth depression. At that time, this differential expression of growth vigor among the 12 lines was thought to be a hereditary characteristic of the $\mathrm{cms}$ plasmon (Tsunewaki et al. 1978). In 1980, on checking the records of their pedigrees, we found that the three vigorous lines were derived from a single (cms)-CS plant, "96-10", of the $\mathbf{F}_{1}$ generation, and that the vigorless lines belonged to different pedigrees. In 1982, we examined the chloroplast DNA of ( $\mathrm{cms}$ )-CS by restriction endonuclease analysis and found that this line carries a plastome identical to that of $A e$. squarrosa. Because our codes for (sqr1)-CS and ( $\mathrm{cms}$ )$\mathrm{CS}$, respectively, are $\mathrm{C} 04$ and $\mathrm{C} 05$, and these two lines were planted next to each other in the field plot at that time, we suspected that a single plant of (sqr1)-CS was misplaced in a row of (cms)-CS. The three vigorous alloplasmics therefore were discarded by 1982, and their production restarted in $1980-1982$ (Fig. 4).

Mistagging such as this is unavoidable when handling a large number of strains over many generations of crossing. Confirmation of such mistakes requires a much time and labor, almost equal to the amounts needed to produce the right alloplasmic lines.

Effect of alloplasmons on the female fertility of common wheat. A comparison of pollen and selfed seed fertilities showed backcrossed seed fertility, a direct measure of female fertility, was much less affected by the alloplasmons. In the averages of the 12 genotypes, backcrossed seed fertility varied from a low of $23.5 \%$ in the $\operatorname{lng}$ plasmon to a high of $75.0 \%$ in the ast 1 plasmon. The 


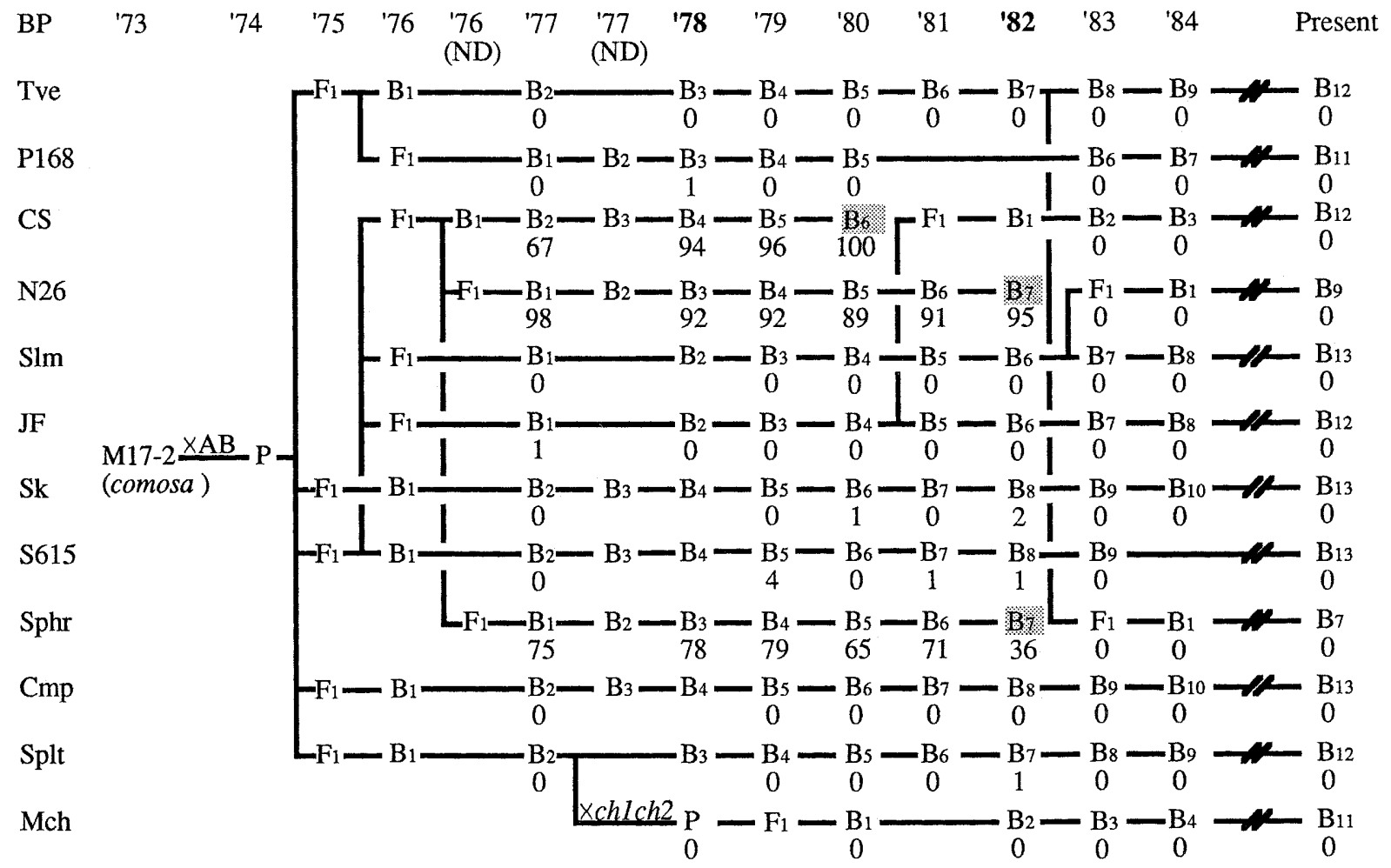

Fig. 4. Breeding history of 12 wheat alloplasmics with the Ae. comosa plasmon. BP, backcross (recurrent pollen) parent. P, $\mathrm{F}_{1}$, and $\mathrm{B}_{1-13}$, parental, 1st filial, and 1st to 13th backcross generations. Number below each generation: Selfed seed fertility (\%). $\mathrm{xAB}, \mathrm{xch} 1 \mathrm{ch2}$ : Bridge crosses made to overcome cross barriers (for details, see text). ND, an extra generation during the indicated year grown in North Dakota, USA, to accelerate the backcrossing program. Screened: Backcrossed generation from which three lines were discarded because plasmon mistagging became evident.

overall average and standard deviation was $63.5 \% \pm$ $11.7 \%$. Because two of the three lowest values were obtained with lines having the $l n g$ and $s p l 2$ plasmons which still carried a gametocidal gene, the variability of female fertility is overestimated. In contrast, both the pollen and selfed seed fertilities showed much wider variations, $0.0 \%$ to $92 \%$, or higher. The overall averages and standard deviations are $58.3 \% \pm 34.1 \%, 42.0 \% \pm 35.1 \%$, and $48.2 \% \pm 35.4 \%$ respectively for the pollen fertility and selfed seed fertilities observed in the greenhouse and field. The variability induced by the same set of 46 alloplasmons in female fertility is only one-third that in male fertility in terms of the standard deviation. Apparently, the fertility of the female gamete is well protected, as compared to that of the male gamete, against genetic stresses such as the introduction of an alien plasmon.

Male fertility and its relation to female fertility in alloplasmic wheats. Pollen fertility is a direct measure of male fertility. Its relation to selfed seed fertility is considered here. A very high positive correlation coefficient, $\mathbf{r}=0.89$, significant at the $0.01 \%$ level, was obtained between the pollen and selfed seed fertilities (Fig. 5a), evidence that selfed seed fertility mainly is determined by pollen fertility. It must be noted that all the lines of high selfed seed fertility had high pollen fertility, whereas the reverse did not hold true. Lines with high pollen fertility showed various degrees of selfed seed fertility, ranging from $0 \%$ to $100 \%$, the majority having high seed fertility. Apparently, a large portion of the pollen grains in certain alloplasmics judged to be fertile on the basis of morphology were actually non-functional in fertilization. Selfed seed fertility therefore is considered to be a more reliable parameter of male fertility than pollen fertility.

The relation of male fertility to female fertility is looked at in two ways; between pollen and backcrossed seed fertilities and between selfed and backcrossed seed fertilities (Fig. 6a, b). A correlation coefficient of $r=0.36$, statistically significant at the $0.01 \%$ level, was obtained between the pollen and backcrossed seed fertilities. This indicates that pollen fertility is only slightly related to female fertility. This slight positive correlation between the two fertilities is assumed to have been caused partly by the weak vigor of some alloplasmic lines and partly by gametocidal genes in some other alloplasmics, both of which affected male and female fertilities. A similar correlation of $r=0.45$, significant at the $0.01 \%$ level, was obtained between the selfed and backcrossed seed fertilities 
a

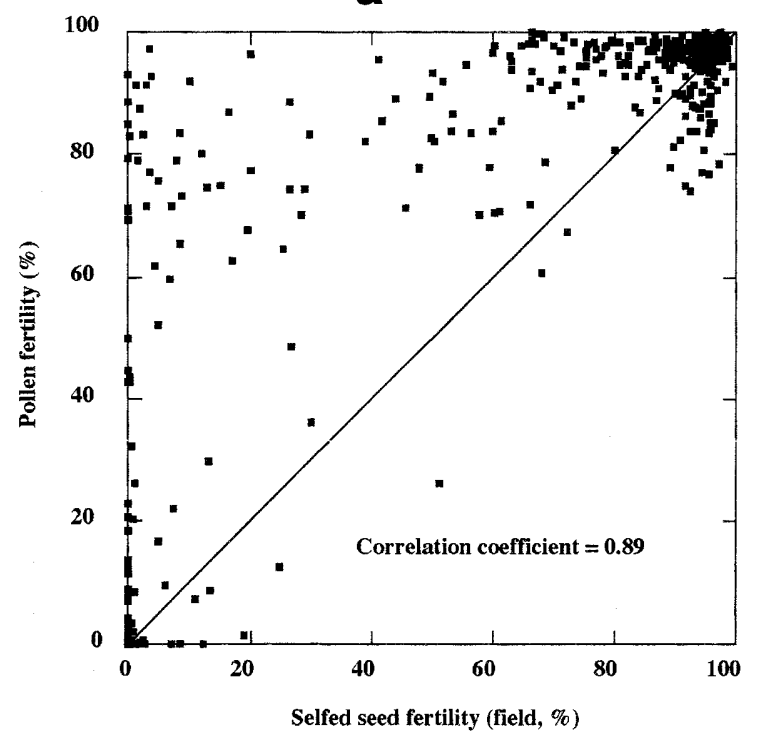

b

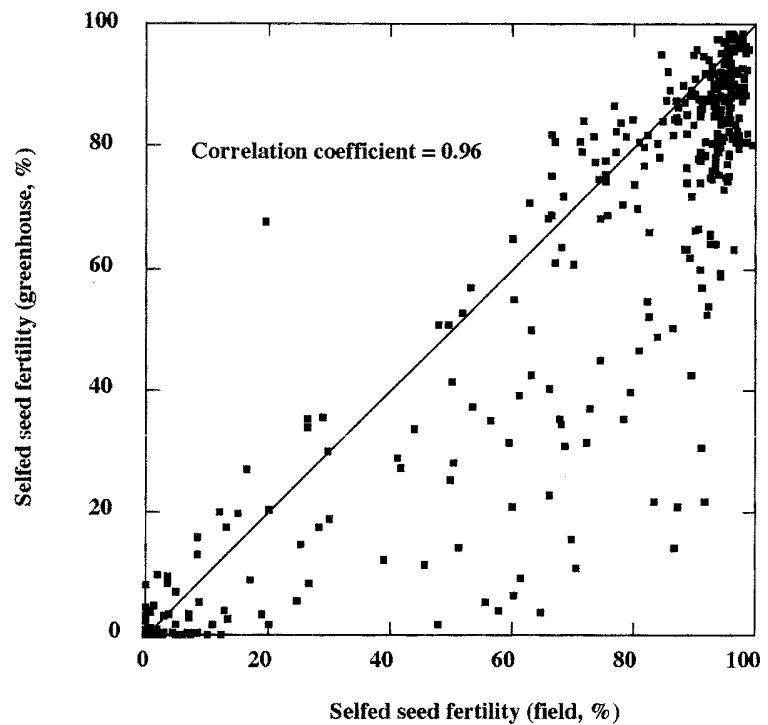

Fig. 5. Scatter diagrams showing the relation of the selfed seed fertility of field-grown plants to their pollen fertility (a), and to the selfed seed fertility of greenhouse-grown plants (b) of the same lines.

a

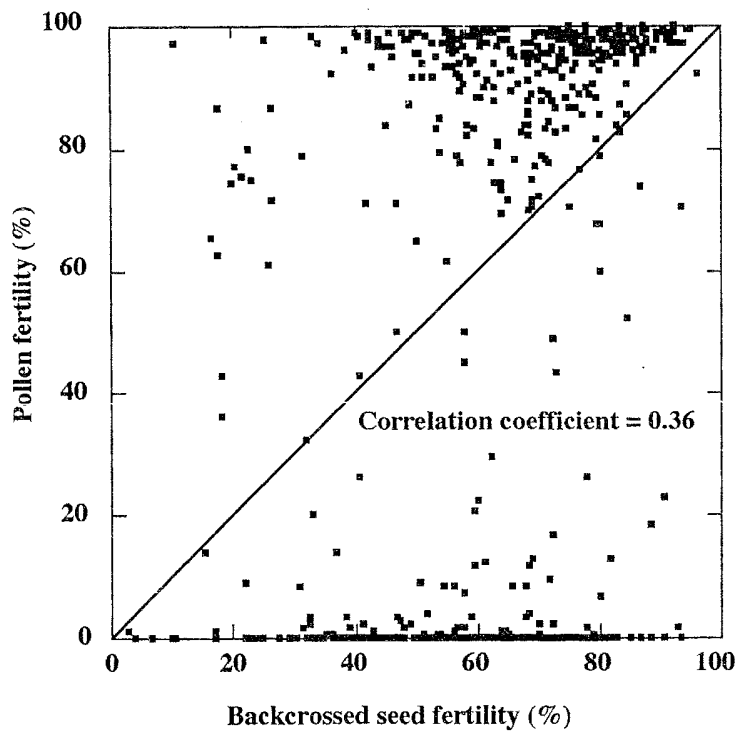

b

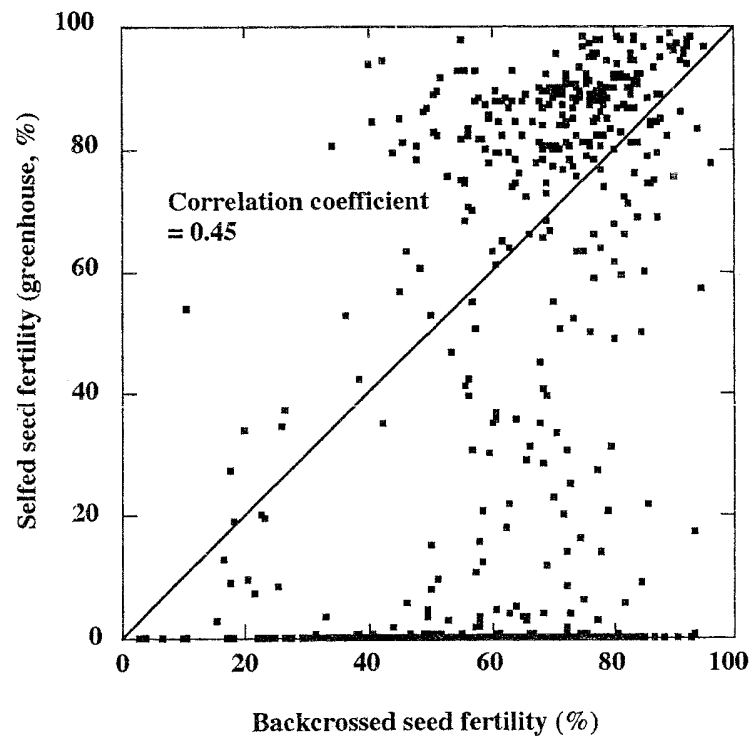

Fig. 6. Scatter diagrams showing the relation of the backcrossed seed fertility of greenhouse-grown plants to pollen fertility (a), and to selfed seed fertility of field-grown plants (b) of the same lines.

of greenhouse-grown plants (Fig. 6b). This also indicates a weak relation between female and male fertility, in confirmation of the previous results. This slight positive correlation is ascribed to the same causes as those that affect the relationship between the pollen and backcrossed seed fertilities.

Difference in seed fertility between greenhouseand field-grown plants. A high positive correlation, $r$ $=0.96$, was found between the selfed seed fertilities of the greenhouse- and field-grown plants (Fig. 5b); the highest of all the coefficients between the pollen and backcrossed and selfed seed fertilities, indicative of the high stability of selfed seed fertility expressed under different environments. The 38 genotype-plasmon combinations, however, had more than $30 \%$ lower fertility when grown in a greenhouse under an artificial long day condition (17-h light) than when grown in the field. Most belonged to the following plasmon type-genotype combinations (plasmon type in parentheses): ( $\left.\mathrm{A}^{2}\right)$-CS; (C)-S615, -Cmp; ( $\left.{ }^{2}\right)-\mathrm{S} 615$, 
-Cmp, -Mch; ( $\left.\mathrm{D}^{2}\right)$-N26, -Cmp; (G)-Mch; $\left(\mathrm{G}^{2}\right)$-Mch; ( $\left.\mathrm{M}^{0}\right)$-CS, -Mch; ( $\left.\mathrm{S}^{1}\right)$-Tve, -JF, -Sphr; (T)-Tve, -N26, -S615; (U)-JF, -Cmp; $\left(\mathrm{U}^{2}\right)$-CS. Apparently 11 plasmon types, $\mathrm{A}^{2}, \mathrm{C}, \mathrm{C}^{2}$, $\mathrm{D}^{2}, \mathrm{G}, \mathrm{G}^{2}, \mathrm{M}^{\mathrm{o}}, \mathrm{S}^{1}, \mathrm{~T}, \mathrm{U}$, and $\mathrm{U}^{2}$, responded to the long day condition by increasing the level of sterility. Of these, the $\mathrm{C}, \mathrm{C}^{2}, \mathrm{D}^{2}, \mathrm{G}, \mathrm{G}^{2}, \mathrm{M}^{0}, \mathrm{~S}^{\mathrm{l}}$, and $\mathrm{U}^{2}$ plasmons apparently reduced fertility by partial to almost complete pistillody of the stamens (Kihara, 1951; Sasakuma and Ohtsuka, 1979; Tsunewaki, 1980). As for the genotype, Tve, CS, N26, JF, $\mathrm{S} 615, \mathrm{Cmp}$, and Mch were clearly more responsive to the long day condition than the other six genotypes.

Classification of 47 plasmons based on their fertility spectra. As discussed earlier, the fertility spectra of selfed seed setting for the greenhouse- and field-grown plants did not markedly differ. On the basis of these spectra, the 47 plasmons studied could be classified into 14 distinct groups (Table 10). The validity of this classification is seen from the smaller within-group standard deviations in each group, as compared to the difference between groups (ref. Tables 8 and 9).

Male sterile plasmons to common wheat and their restorers. If a line with less than $5 \%$ selfed seed fertility under field conditions is treated as male-sterile, the plasmon types given in Table 11 can be considered male sterile plasmons to common wheat (ref. Table 9). From Tables 10 and 11, it is clear that each subtype plasmon differs only slightly from plasmons of the corresponding major type with the exception of the $\mathrm{T}^{2}$ subtype.

Wheat genotypes which showed high selfed seed fertility in the presence of either male sterile plasmon are considered to be restorers to their male sterile plasmon. Of the large number of combinations between male sterile lines and their restorers (given before and after the slash in the following), nine combinations, (crs)-N26/CS of fertility spectrum type I'; (kts)-Splt/CS, (unr)-Slm/Cmp, and ( $m t c 1$ )$\mathrm{Slm} / \mathrm{CS}$ of type II; (umb)-Slm/CS of type IV; (ovt)-N26/

Table 10. Classification of the 47 plasmons into 14 fertility spectrum types

\begin{tabular}{|c|c|c|}
\hline Spectrum type & Plasmon type & No. of plasmons \\
\hline $\mathrm{I}$ & $\mathrm{B}, \mathrm{S}, \mathrm{S}^{\mathrm{b}}$ and $\mathrm{D}$ & 12 \\
\hline $\mathrm{I}^{\prime}$ & $\mathrm{D}^{2}$ & 4 \\
\hline II & $\mathrm{N}, \mathrm{S}^{\mathrm{v}}$ and $\mathrm{T}$ & 6 \\
\hline III & $\mathrm{S}^{1}$ & 1 \\
\hline III' & $\mathrm{S}^{12}$ & 1 \\
\hline IV & $\mathrm{U}$ & 7 \\
\hline IV' & $\mathrm{U}^{2}$ & 1 \\
\hline $\mathrm{V}$ & $\mathrm{C}^{2}$ & 1 \\
\hline VI & $\mathrm{M}^{\circ}$ & 1 \\
\hline VII & G & 5 \\
\hline VII' & $\mathrm{G}^{2}$ & 1 \\
\hline VIII & $\mathrm{C}$ & 2 \\
\hline IX & $\mathrm{A}^{2}$ & 1 \\
\hline $\mathrm{X}$ & $\mathrm{A}, \mathrm{M}, \mathrm{M}^{\mathrm{h}}$ and $\mathrm{T}^{2}$ & 4 \\
\hline
\end{tabular}

Table 11. Completely male sterile plasmons to common wheat

\begin{tabular}{ll}
\hline $\begin{array}{l}\text { Plasmon } \\
\text { type }\end{array}$ & $\begin{array}{l}\text { Genotype expressing male } \\
\text { sterility }\end{array}$ \\
\hline $\mathrm{A}, \mathrm{M}^{\mathrm{h}}$ & All 12 genotypes \\
$\mathrm{A}^{2}$ & All but CS \\
$\mathrm{T}^{2}$ & All but P168 \\
$\mathrm{M}$ & All but S615 \\
$\mathrm{G}$ & All but Splt, Mch \\
$\mathrm{G}^{2}$ & All but CS, Mch \\
$\mathrm{C}$ & All but P168, S615, Cmp \\
$\mathrm{M}^{\circ}$ & All but P168, CS, Mch \\
$\mathrm{U}^{2}$ & All but P168, CS, N26, JF, Cmp \\
$\mathrm{U}$ & Tve, N26, Slm, Sphr, Splt, Mch \\
$\mathrm{C}^{2}$ & N26, Slm, JF, Sk, Sphr \\
$\mathrm{S}^{1}$ & N26, Slm, Splt, Mch \\
$\mathrm{S}^{12}, \mathrm{~S}^{\mathrm{v}}, \mathrm{T}$ & Slm, Splt, Mch \\
$\mathrm{N}$ & Splt, Mch \\
$\mathrm{B}, \mathrm{D}, \mathrm{D}^{2}, \mathrm{~S}, \mathrm{~S}^{b}$ & (None) \\
\hline
\end{tabular}

P168, and (ovt)-Sk/CS of type VI; (tmp)-CS/Splt of type VII; and (cdt1)-CS/Cmp of type VIII, respectively, were subjected to the monosomic and/or telosomic analysis by Murai and Tsunewaki (1994), Mukai and Tsunewaki (1979), Mukai (1983), Tsujimoto and Tsunewaki (1984b), Tsunewaki (1974), Tahir and Tsunewaki (1971), Tsunewaki (1982), Tahir and Tsunewaki (1969) and Tsunewaki (1974) to identify the number and chromosomal location of the fertility-restoring genes. The findings indicate that a single, or a few, dominant major genes (mainly located on the 1B, 6B or 1D chromosome) together with several minor genes, control full fertility restoration against the respective male sterile plasmon (Tsunewaki, 1993, for review).

A single wheat line or a few lines which had 29 alloplasmons were received from the persons named in Table 2. These were a part of the source of the plasmons used in the present program. We thank all these people for their courtesy in providing those valuable materials thereby allowing us to study the complete spectrum of plasmon diversity in the Triticum and Aegilops species. The early stage of the present backcrossing program to produce alloplasmic wheat lines was carried out with the help of many coworkers, of whom Y. Nakai, T. Hori, T. R. Endo, Y. Mukai, S. Tsuji, M. Murata, and T. Iwai must be especially thanked for their contributions to the establishment of the entire backcrossing program. G.-Z. Wang was supported by the Japanese Government (Monbusho) Scholarship.

\section{REFERENCES}

Endo, T. R. (1979) Selective gametocidal action of a chromosome of Aegilops cylindrica in a cultivar of common wheat. Wheat Inf. Serv. 50, 24-28.

Endo, T. R. (1990) Gametocidal chromosomes and their induction of chromosome mutations in wheat. Jpn. J. Genet. 65, 135152.

Endo, T. R. and Katayama, Y. (1978) Finding of a selectively retained chromosome of Aegilops caudata L. in common wheat. Wheat Inf. Serv. 47-48, 32-35. 
Endo, T. R. and Tsunewaki, K. (1975) Sterility of common wheat with Aegilops triuncialis cytoplasm. J. Hered. 66, 13-18.

Fukasawa, H. (1959) Nucleus substitution and restoration by means of successive backcrosses in wheat and its related genus Aegilops. Jpn. J. Bot. 17, 55-91.

Kihara, H. (1951) Substitution of nucleus and its effects on genome manifestations. Cytologia 16, 177-193.

Kihara, H. and Tanaka, M. (1970) Addendum to the classification of the genus Aegilops by means of genome-analysis. Wheat Inf. Serv. 30, 1-2.

Kimber, G. and Tsunewaki, K. (1988) Genome symbols and plasma types in the wheat group. Proc. 8th Int. Wheat Genet. Symp. Cambridge 1209-1210.

Kobayashi, M. and Tsunewaki, K. (1980a) Haploid induction and its genetic mechanism in alloplasmic common wheat. J. Hered. 71, 9-14.

Kobayashi, M. and Tsunewaki, K. (1980b) Production of an effective haploid inducer utilizing the kotschyi and variabilis cytoplasm. In: Genetic Diversity of the Cytoplasm in Triticum and Aegilops (ed.: K. Tsunewaki), pp. 250-265. Japan Society for Promotion of Science, Tokyo.

Maan, S. S. (1975a) Cytoplasmic variability and speciation in Triticinae. In: Prairie: A Multiple Review (ed.: M. K. Wali), pp. 255-281. Univ. North Dakota Press, Grand Forks, ND.

Maan, S. S. (1975b) Exclusive preferential transmission of an alien chromosome in common wheat. Crop Sci. 15, 287-292.

Michaelis, H. (1954) Cytoplasmic inheritance in Epilobium and its theoretical significance. Adv. Genet. 6, 288-401.

Miller, T. E., Hutchinson, J. and Chapman, V. (1982) Investigation of a preferentially transmitted Aegilops sharonensis chromosome in wheat. Theor. Appl. Genet. 61, 27-33.

Mukai, Y. (1981) Genetic studies of the wheat haploids induced by alien cytoplasms. Mem. Osaka Kyoiku Univ. Ser. III 30, 3155.

Mukai, Y. (1983) Determination of the chromosome arm carrying a male fertility-restoring gene against the cytoplasm of Aegilops uniaristata in wheat. Mem. Osaka Kyoiku Univ. Ser. III 32, 43-53.

Mukai, Y. and Tsunewaki, K. (1979) Basic studies on hybrid wheat breeding. VIII. A new male sterility-fertility restoration system in common wheat utilizing the cytoplasms of Aegilops kotschyi and Ae. variabilis. Theor. Appl. Genet. 54, 153-160.

Murai, K. and Tsunewaki, K. (1994) Genetic analysis on the fertility restoration by Triticum aestivum cv. Chinese Spring against photoperiod-sensitive cytoplasmic male sterility. Jpn. J. Genet. 69, 195-202.

Panayotov, I. (1983) The cytoplasm in Triticinae. Proc. 6th Int. Wheat Genet. Symp. Kyoto 481-497.

Rieger, R., Michaelis, A. and Green, M. M. (1991) Glossary of Genetics, 5th Edition. Springer-Verlag, Berlin.

Sasakuma, T. and Ohtsuka, I. (1979) Cytoplasmic effects of Aegilops species having D genome in wheat. I. Cytoplasmic differentiation among five species regarding pistillody induction. Seiken Ziho 27-28, 59-65.
Snedecor, G. W. (1955) Statistical Methods (6th edition). Iowa State College Press, Ames, IA.

Stubbe, W. (1964) The role of the plastome in evolution of the genus Oenothera. Genetica 35, 28-33.

Suemoto, H. (1983) The cytoplasm of tetraploid wheats. II. Proc. 6th Int. Wheat Genet. Symp. Kyoto 499-506.

Tahir, C. M. and Tsunewaki, K. (1969) Monosomic analysis of Triticum spelta var. duhamelianum, a fertility restorer for $T$. timopheevi cytoplasm. Jpn. J. Genet. 44, 1-9.

Tahir, C. M. and Tsunewaki, K. (1971) Monosomic analysis of fertility-restoring genes in Triticum aestivum strain P168. Can. J. Genet. Cytol. 13, 14-19.

Tsujimoto, H. and Tsunewaki, K. (1984a) Gametocidal genes in wheat and its relatives. I. Genetic analyses in common wheat of a gametocidal gene derived from Aegilops speltoides. Can. J. Genet. Cytol. 26, 78-84.

Tsujimoto, H. and Tsunewaki, K. (1984b) Chromosome location of a fertility-restoring gene of a common wheat Chinese Spring for the Ae. mutica cytoplasm. Wheat Inf. Serv. 58, 4-8.

Tsujimoto, H. and Tsunewaki, K. (1985) Gametocidal genes in wheat and its relatives. II. Suppressor of the chromosome 3C gametocidal gene of Aegilops triuncialis. Can. J. Genet. Cytol. 27, 178-185.

Tsujimoto, H. and Tsunewaki, K. (1988) Gametocidal genes in wheat and its relatives. III. Chromosomal location and effects of two Aegilops speltoides-derived gametocidal genes in common wheat. Genome 30, 239-244.

Tsunewaki, K. (1974) Monosomic analysis of two restorers to Ae. caudata and Ae. umbellulata cytoplasms. Jpn. J. Genet. 49, 425-433.

Tsunewaki, K. (1980) Genetic Diversity of the Cytoplasm in Triticum and Aegilops. Japan Society for Promotion of Science, Tokyo.

Tsunewaki, K. (1982) Monosomic analysis on the fertility restoration by Triticum aestivum cv. Chinese Spring against Aegilops ovata cytoplasm. Jpn. J. Genet. 57, 513-525.

Tsunewaki, K. (1993) Genome-plasmon interactions in wheat (review). Jpn. J. Genet. 68, 1-34.

Tsunewaki, K. (1996) Plasmon analysis as the counterpart of genome analysis. In: Methods of Genome Analysis in Plants (ed.: P. P. Jauhar), pp. 271-299. CRC Press, New York.

Tsunewaki, K. and Mukai, Y. (1990) Wheat haploids through the Salmon method. In: Biotechnology in Agriculture and Forestry. Vol. 13. Wheat (ed.: Y. P. S. Bajaj), pp. 460-478. Springer-Verlag, Berlin.

Tsunewaki, K. and Ogihara, Y. (1983) The molecular basis of genetic diversity among cytoplasms of Triticum and Aegilops species. II. On the origin of polyploid wheat cytoplasms as suggested by chloroplast DNA restriction fragment patterns. Genetics 104, 155-171.

Tsunewaki, K., Mukai, Y. and Endo, T. R. (1978) On the descent of the cytoplasms of polyploid species in Triticum and Aegilops. Proc. 5th Int. Wheat Genet. Symp. 1, 261-272.

Wettstein, F. von (1924) Morphologie und Physiologie der Formwechels der Moose auf genetischer Grundlage. I. Z. Indukt. Abstammungs Vererbungsl. 33, 1-236. 